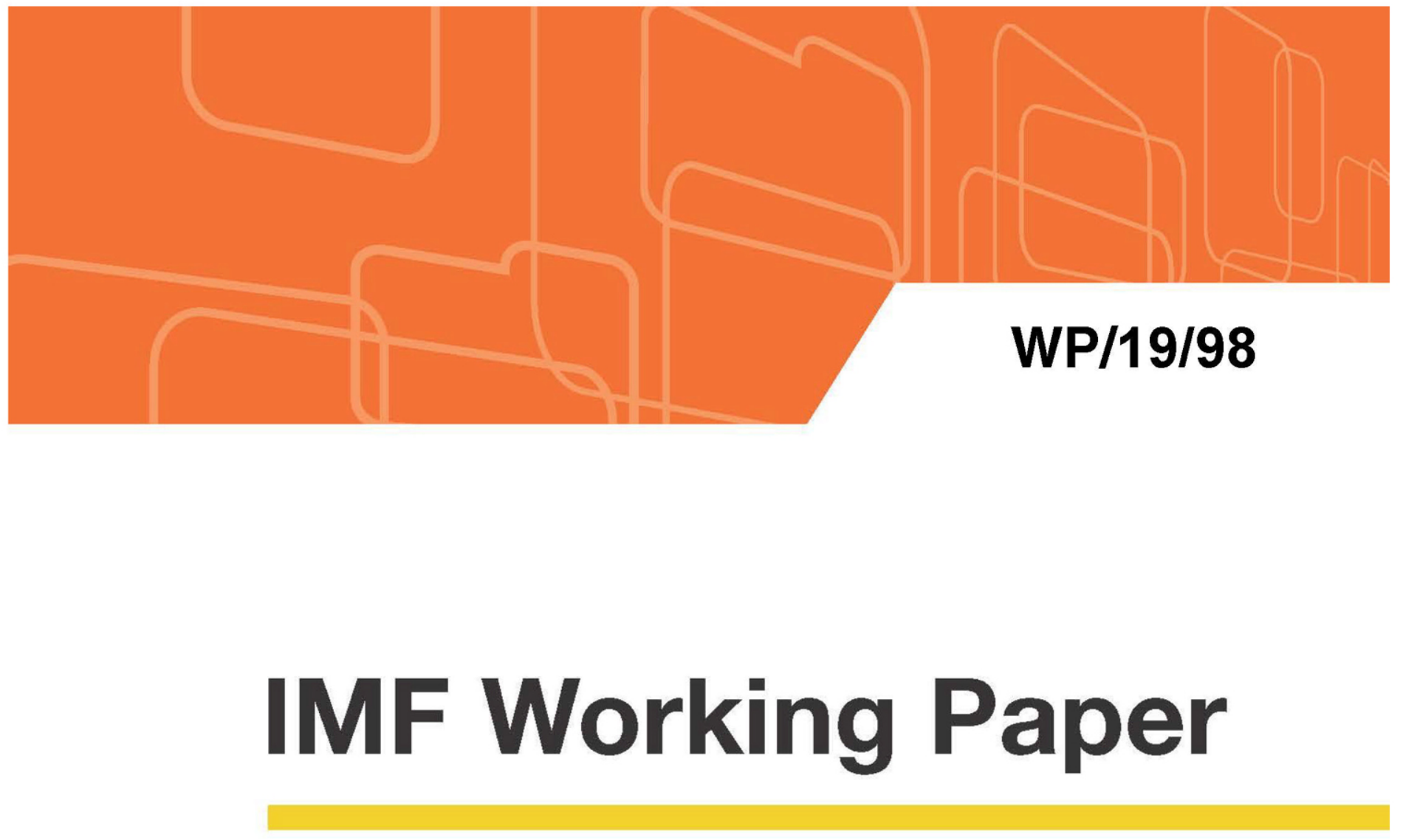

\title{
The Optimal Turnover Threshold and \\ Tax Rate for SMEs
}

by Feng Wei and Jean-François Wen

IMF Working Papers describe research in progress by the author(s) and are published to elicit comments and to encourage debate. The views expressed in IMF Working Papers are those of the author(s) and do not necessarily represent the views of the IMF, its Executive Board, or IMF management.

I N T E R N A T I O N A L M O N E T A R Y F U N D 


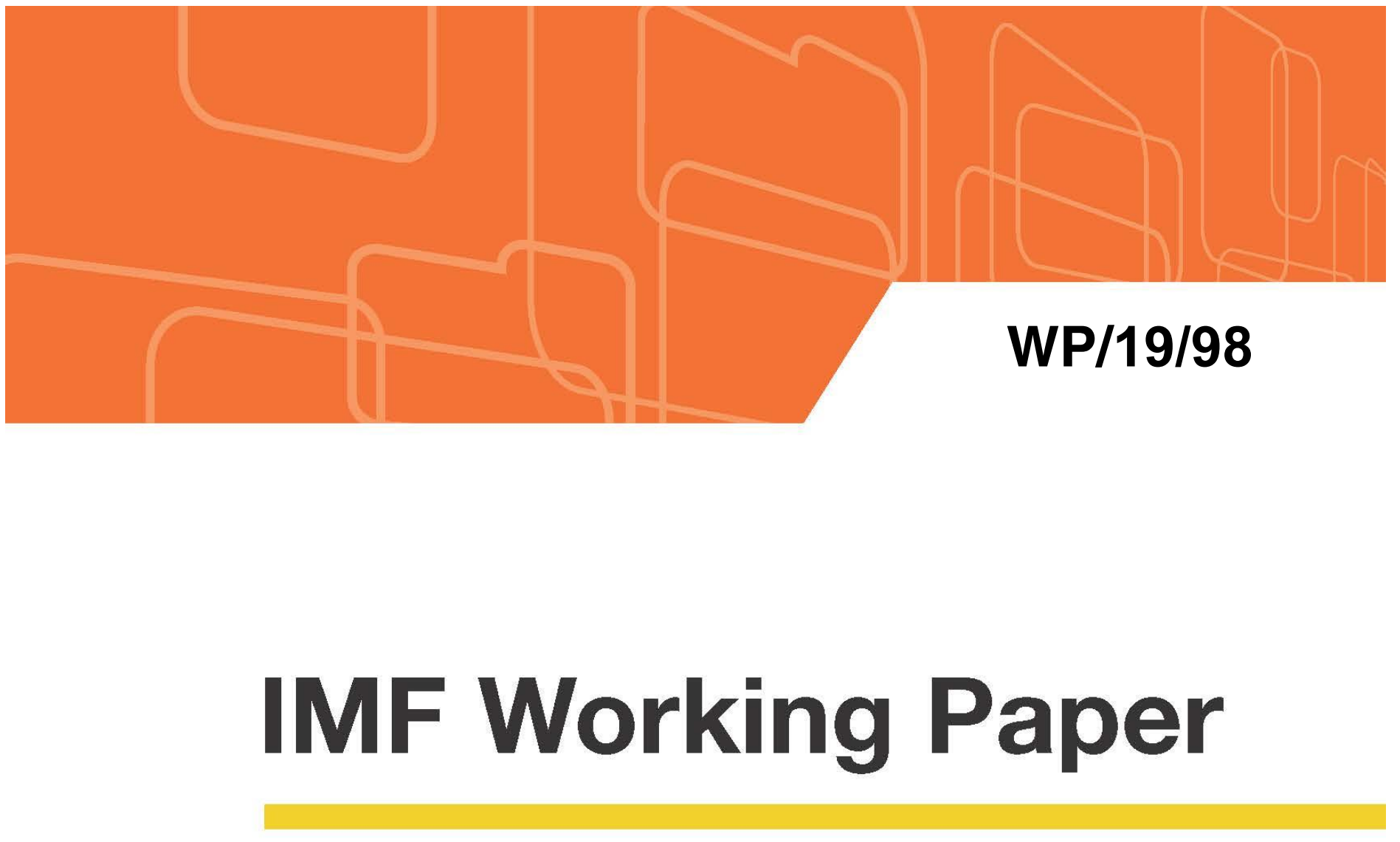

\section{The Optimal Turnover Threshold and Tax Rate for SMEs}

by Feng Wei and Jean-François Wen

IMF Working Papers describe research in progress by the author(s) and are published to elicit comments and to encourage debate. The views expressed in IMF Working Papers are those of the author(s) and do not necessarily represent the views of the IMF, its Executive Board, or IMF management.

$$
\text { I N T E R N A T I O N A L M O N E T A R Y F U N D }
$$




\title{
IMF Working Paper
}

Fiscal Affairs Department

\section{The Optimal Turnover Threshold and Tax Rate for SMEs \\ Prepared by Feng Wei and Jean-François Wen}

Authorized for distribution by Ruud De Mooij

May 2019

\section{IMF Working Papers describe research in progress by the author(s) and are published to elicit comments and to encourage debate. The views expressed in IMF Working Papers are those of the author(s) and do not necessarily represent the views of the IMF, its Executive Board, or IMF management.}

\begin{abstract}
Presumptive income taxes in the form of a tax on turnover for SMEs are pervasive as a way to reduce the costs of compliance and administration. We analyze a model where entrepreneurs allocate labor to the formal and informal sectors. Formal sector income is subjected either to a corporate income tax or a tax on turnover, depending on whether their turnover exceeds a threshold. We characterize the private sector equilibrium for any given configuration of tax policy parameters (corporate income tax rate, turnover tax rate, and threshold). Given private behavior, social welfare is optimized. We interpret the first-order conditions for welfare maximization to identify the key margins and then simulate a calibrated version of the model.
\end{abstract}

JEL Classification Numbers: C61, H21, H25, H320, O17

Keywords: Turnover Tax, Threshold, Corporate Income Tax, Tax Compliance, Informality Authors’ E-Mail Addresses: fwei@ucalgary.ca, jwen@imf.org 


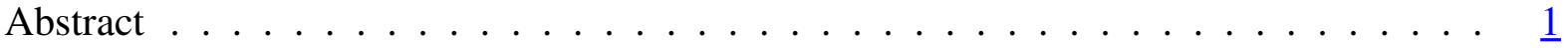

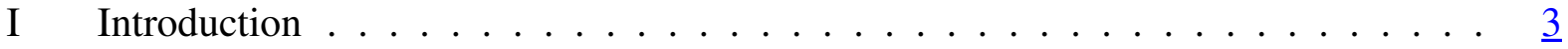

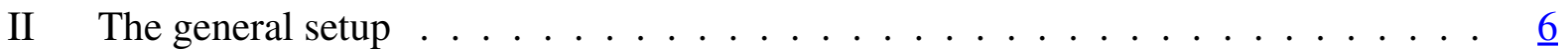

III Comparing the presumptive and regular regimes ............. $\underline{8}$

A All firms are in the regular regime ............... $q^{9}$

B All firms in the presumptive regime ............... . . . . . . . . . . .

C Comparison of welfare between the assigned regimes $\ldots \ldots \ldots$

IV Presumptive regime with a sales threshold . . . . . . . . . . . . 11

A Partitioning the distribution of firms .................. 11

B Constructing the sets using sales diagrams $\ldots \ldots \ldots \ldots$

V Social welfare optimization . . . . . . . . . . . . . . 19

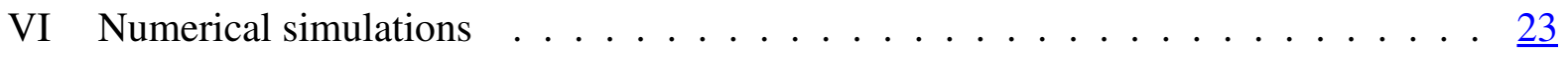

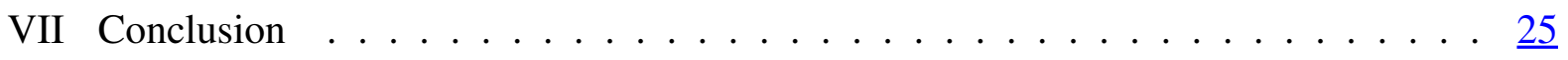

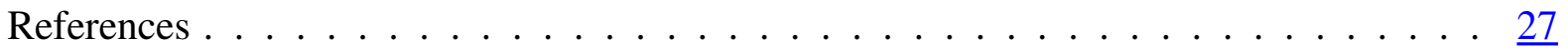

Appendix: Proofs . . . . . . . . . . . . . . . . . . . . 29

Proof of Proposition $2 \ldots \ldots \ldots \ldots \ldots$

Proof of Proposition $4 \ldots \ldots \ldots \ldots \ldots \ldots$

Proof of Proposition $5 \ldots \ldots \ldots \ldots \ldots$

First-order condition of welfare for $t^{c} \ldots \ldots \ldots \ldots$ 


\section{INTRODUCTION}

Turnover taxes are widely used as "presumptive" or "simplified" income tax regimes for small and medium-sized enterprises (SMEs) to reduce the costs of tax compliance and administration. The rationale for this approach is that sales (turnover) are relatively easier to measure, record, and verify than profit. As the fixed costs of complying with and administrating regular business income taxation makes the costs regressive, ${ }^{1}$ presumptive regimes are intended for firms with sales below a threshold. However, a tax on turnover distorts the input choice of firms, unlike a well-designed tax on profits, thereby reducing productivity. Countries with presumptive regimes include France, Italy, Portugal, but especially developing and transition economies. Table 1 shows the thresholds and turnover tax rates currently in force in various countries. ${ }^{2}$ There is significant variation in the observed turnover tax rates and thresholds for SMEs. For example, in Kenya, firms with a turnover below $\$ 49,000$ are subjected to a turnover tax rate of $3 \%$ in lieu of the regular corporate income tax rate of $30 \%$; in Seychelles the threshold and turnover tax rate are $\$ 74,000$ and $1.5 \%$; in Mauritania they are $\$ 84,000$ and 3\%; in Guinea the threshold is $\$ 16,500$ with a turnover tax rate of $5 \%$, while in Belarus they are $\$ 625,000$ and $5 \% .^{3}$

Despite the prevalence of turnover taxes for SMEs, there is little theoretical guidance for determining the optimal threshold separating the presumptive and regular tax regimes, nor on the relationships between the threshold and the tax rates on turnover and corporate income. A very commonly advocated rule of thumb for the threshold of the presumptive income tax regime is to use the VAT threshold. The logic is that firms large enough to comply with the bookkeeping requirements of the VAT ought also to be able to comply with business income taxation. However, the optimal threshold for income taxation is driven by various margins that are not the same as for the optimal VAT. One such consideration is the gap between the regular corporate income tax rate and the presumptive tax rate on sales. A "good practice" recommendation in reports by international organizations is that the effective tax rate on income, implied by the turnover tax, should be more onerous at the threshold than the burden under the regular tax, in order to encourage firms to "graduate" to the regular system. But this advice neglects the cost of tax compliance, the avoidance of which is the very purpose of the presumptive regime. Another common policy recommendation is that the presumptive tax should be "neutral," in the sense of equalizing the after-tax profit margins across tax

\footnotetext{
${ }^{1}$ For taxpayers, there is the time spent on bookkeeping tasks related to tax compliance and the cost of purchasing specialized accounting software. For the authorities, the cost of enforcing tax collection by visits to the premises and audits is largely independent of the amount of tax due.

${ }^{2}$ There can be additional eligibility criteria for the presumptive regime and in many countries a company below the threshold can elect to be subjected to the regular regime. For example, in Belarus firms in the simplified regime can have a maximum of 50 employees and can elect for the regular corporate income tax regime. In some cases, only unincorporated businesses are eligible. For example, in France the simplified regime is available only to unincorporated sole proprietors and partnerships.

${ }^{3}$ See Engelschalk and Loeprick (2015) and International Tax Dialogue (2007) for more examples of presumptive income taxes. See Logue and Vettori (2001) for a discussion of presumptive regimes in the context of the tax compliance of SMEs in the United States.
} 
Table 1. International practices on turnover thresholds and tax rates

\begin{tabular}{|c|c|c|c|}
\hline Country & Threshold (USD) & Turnover tax rate (\%) & Corporate income tax rate (\%) \\
\hline \multicolumn{4}{|l|}{ Eastern Europe } \\
\hline Armenia & 122,400 & 5 (trading), 3.5 (production) & 20 \\
\hline Azerbaijan & 346,000 & 4 (in Baku), 2 (outside Baku) & 20 \\
\hline Belarus & 625,000 & 5 (3 for VAT payers) & 18 \\
\hline Latvia & 45,600 & 15 (includes payroll tax) & 20 \\
\hline Russia & $2,250,000$ & 6 & 15 \\
\hline Ukraine & 185,000 & 5 (3 for VAT payers) & 18 \\
\hline Uzbekistan & 120,000 & 4 & 14 \\
\hline \multicolumn{4}{|l|}{ Africa } \\
\hline Algeria & 255,000 & 5 & 19 \\
\hline Angola & 250,000 & 2 & 30 \\
\hline Congo (DRC) & 122,000 & 1 (goods), 2 (services) & 35 \\
\hline Congo (Brazzaville) & 170,000 & 7.7 & 30 \\
\hline Cameroon & 85,000 & 2.2 & 33 \\
\hline Guinea & 16,500 & 5 & 25 \\
\hline Kenya & 49,000 & 3 & 30 \\
\hline Liberia & 18,600 & 4 & 25 \\
\hline Madagascar & 56,000 & 5 & 20 \\
\hline Mauritania & 84,000 & 3 & 25 \\
\hline Rwanda & 22,000 & 3 & 30 \\
\hline Senegal & 87,300 & 4 - 8 (progressive rates) & 30 \\
\hline Seychelles & 74,000 & 1.5 & 25 \\
\hline Tanzania & 8,800 & 3 to 5.3 & 30 \\
\hline Uganda & 40,500 & 1.5 & 30 \\
\hline Zambia & 67,200 & 3 & 35 \\
\hline \multicolumn{4}{|l|}{ Asia } \\
\hline Indonesia & 331,200 & 1 & 25 \\
\hline \multicolumn{4}{|l|}{ Western Europe } \\
\hline Austria & 250,800 & 0.22 & 25 \\
\hline France & 94,400 & 1.7 (industrial/commercial), 2.2 (non-commercial) & 28 \\
\hline Italy & 39,900 & 0.06 (food), 0.117 (professionals), etc. & 27.9 \\
\hline Portugal & 228,000 & 0.15 & 21 \\
\hline
\end{tabular}

Sources : Miscellaneous tax guides and IBFD library. Notes : US dollar exchange rate as of December 2018.

regimes. However, in any interior equilibrium there will, by definition, be some firms that are indifferent between the two tax regimes, so that the recommendation for setting the optimal policy is vacuous without a detailed model, unless it is assumed that all firms have identical pre-tax profit margins. At the same time, moreover, care must be taken in setting the turnover tax rate, so as not to push firms in the presumptive system down into the untaxed but lowproductivity informal sector, or, in some cases, into a fixed tax regime ("patent system") intended for subsistence self-employment activities (Coolidge and Yilmaz, 2016). Thus, the optimal design of a presumptive tax regime is a complex issue.

This paper is the first to study the optimal sales threshold separating the presumptive and regular corporate income tax regimes and the corresponding optimal tax rates. We identify the key margins determining the welfare optimum and show how the optimal policies vary with the marginal cost of public funds, with administrative costs, and with productivity shifts. Additionally, we show how the optimal threshold and turnover tax rate are affected by changes in the corporate income tax rate. Our study is related to several strands of the literature. First, our analysis of an optimal turnover threshold separating two tax regimes is complementary to 
Keen and Mintz (2004) on the VAT threshold and Dharmapala et al. (2011) on the threshold between a tax on sales and a fixed fee regime, while contributing to our understanding of the behavior of firms confronted by "notches" in tax schedules (Kleven and Waseem, 2013, Kanbur and Keen, 2014). Important differences with Kanbur and Keen (2014) are our inclusion of an intensive margin and our characterization of not only the optimal threshold, but also the optimal tax rates. While solutions for the optimal threshold can be derived in the absence of behavioral responses, akin to the "benchmark" in Kanbur and Keen (2014), marginal adjustments are crucial for interior solutions of optimal tax rates. ${ }^{4}$

The structure of our model resembles the model of Keen and Mintz (2004), except for an important distinction. While the heterogeneity of firms in Keen and Mintz (2004) stems from differences in productivity, in our model the heterogeneity is in terms of marginal costs of production. This is crucial for studying turnover taxes, because it is precisely the non-deductibility of costs that generates the inefficiencies associated with turnover taxation. Thus, an interesting finding arising from adjustments along the intensive margin in our model is that, depending on the tax rates and the size of compliance costs, both the higher-cost firms and the lowercost firms may locate in the presumptive regime, leaving only middle-cost firms in the regular regime. Best et al. (2015) analyze a related tax system, whereby firms are taxed on profits, provided the tax liability is greater than an alternative minimum tax levied on turnover. The turnover tax in this case does not economize on compliance costs, since every firm must calculate and report its liabilities under the regular regime. ${ }^{5}$ The heterogeneity of firm's marginal costs in our model also makes it suitable for considering the effects of another approach used to simplify taxation for small businesses, in which a turnover threshold is used to separate larger businesses subject to VAT and smaller businesses subject to an alternative turnover tax system $(\mathrm{Zu}, 2018)$.

Our main findings are that the optimal threshold is generally between about $\$ 100,000$ and $\$ 150,000$, depending on the value added per firm of a country, and the optimal turnover tax rate is close to $3 \%$ in our benchmark calculation, if a single tax rate is being applied to all sectors of the economy. However, according to our estimates, the optimal turnover tax rate is higher and the optimal threshold is lower for Sub-Saharan Africa. Comparing our results with actual the practices described in Table 1, we find that, while many countries have appropriate policies, others deviate substantially from our prescriptions for welfare maximization.

The paper is structured as follows. Section 2 provides the basic description of the model. Section 3 contrasts the theoretical properties of the corporate income tax and the turnover tax by supposing that only one regime is used. Section 4 analyzes the choices of firms when the presumptive and regular tax regimes coexist. Section 5 examines the first-order conditions of the social welfare function with respect to the threshold and tax rates, given the private sector equilibrium responses. Section 6 provides numerical simulations of the optimal policies for a benchmark case and for countries at differing levels of economic development. Section 7 concludes. Proofs are in Appendix 1 unless they follow directly from the discussion.

\footnotetext{
${ }^{4}$ However, unlike Kanbur and Keen (2014), we do not extend the analysis to consider multiple thresholds and income concealment.

${ }^{5}$ The purpose of the minimum tax is to reduce the opportunity for evading the corporate income tax.
} 


\section{THE GENERAL SETUP}

We assume that every individual allocates one unit of labor time between an amount $L$ for production in the formal sector and $1-L$ for production in the informal sector. Both sectors produce final goods, but the production technologies differ. An individual's output in the formal sector is $f(L)$, where $f$ is increasing and strictly concave (with $f(0)=0$ and derivatives indicated by $f^{\prime}>0$ and $f^{\prime \prime}<0$ ). In contrast, there is a constant rate of productivity $w$ in the informal sector. The informal-sector good serves as the numeraire and, by definition of informality, the earnings $w(1-L)$ are untaxable. Production in the formal sector requires, in addition to labor supply, some amount $\lambda>0$ of an imported intermediate good, per unit of output. The country is small in world markets, with the price of the formal-sector final good and the imported intermediate good fixed at $p$ and $p_{I}$, respectively. The value of $\lambda$ is individualspecific. Thus, for a given value of $\lambda$ the cost of the intermediate good per unit of output produced is $c=p_{I} \lambda$ and we can differentiate between the heterogeneous abilities of individuals, or "firms" by assuming directly that $c$ is distributed according to a twice differentiable cumulative distribution function $H(c)$, with density $h(c)$ and support $c \in[0,1]{ }^{6}$

Two linear tax regimes are considered for the income earned in the formal sector. In the regular regime, the cost of the intermediate input is tax deductible, with formal-sector profits taxed at the rate $t^{c}<1$, while in the presumptive regime the tax rate is $t<1$ and costs are not deductible. Thus, the regular regime represents a corporate income tax and the presumptive regime corresponds to a tax on turnover. Firms with sales inferior to a fixed threshold $\bar{Z}$ are placed in the presumptive regime. Finally, it is assumed that an individual subjected to the regular regime faces a fixed compliance cost $\Gamma \geq 0$ and imposes a fixed administrative cost $A>0$ on the tax authority. For simplicity, we assume that there are no compliance or administration costs associated with the presumptive regime. We can represent net profits by

$$
\pi(L) \equiv \rho f(L(\rho))+w(1-L(\rho))-I^{R} \Gamma
$$

where the "net price" is

$$
\rho= \begin{cases}p^{P} \equiv(1-t) p-c & \text { if in the presumptive regime } \\ p^{R} \equiv\left(1-t^{c}\right)(p-c) & \text { if in the regular regime }\end{cases}
$$

and $I^{R}$ is an indicator function, which equals 1 when the firm is subjected to the regular regime and 0 if it is in the presumptive regime.

\footnotetext{
${ }^{6}$ Similarly to Keen and Mintz (2004), an alternative interpretation of the model makes the reference to "firms" more natural. The variable $L$ can be thought of as the amount of capital a firm invests in the taxed sector, subject to a fixed required rate of return, represented by $w$. Aside from an irrelevant constant stemming from the fixed time endowment, this interpretation gives the same formal structure as the self-employed labor model that we have described. In this case, however, no inferences can be drawn about the prevalence of informal activities, since $1-L$ is not constrained to be positive.
} 
Ignore the sales threshold for the moment. The first-order condition for unconstrained profitmaximization by a type- $c$ firm in a given tax regime is

$$
\rho f^{\prime}\left(L^{*}\right)-w=0
$$

with the net price $\rho$ being a function of $c$ via (2). The second-order condition, $\rho f^{\prime \prime}\left(L^{*}\right)<0$, requires $\rho$ to be positive. Let $L(\rho) \equiv L^{*}$ and define the optimized profit function using (3) and (1) as

$$
\pi^{*}(\rho)=\pi(L(\rho))
$$

and let

$$
\begin{aligned}
& \pi^{R}(c) \equiv \pi^{*}\left(p^{R}(c)\right) \\
& \pi^{P}(c) \equiv \pi^{*}\left(p^{P}(c)\right)
\end{aligned}
$$

Since informal sector activities are untaxed, the minimum net profit of a firm in the regular regime is $\pi^{R}=w-\Gamma$ (obtained by setting $L=0$, which becomes optimal as $t^{c}$ approaches unity). ${ }^{7}$ Similarly, a firm in the presumptive regime may encounter a tax rate $t$ such that its net price, $p^{P}$, is negative. In this case, the solution for $L^{*}$ given by (3) would violate the secondorder condition. Such a firm would choose the corner solution of retreating entirely to the informal sector with $L^{*}=0$ and earn $w$ (recall there is no compliance cost for the presumptive regime).

Observe that, at interior solutions for $L^{*}$,

$$
\begin{aligned}
\frac{d \pi^{*}}{d \rho} & =f\left(L^{*}\right)>0 \\
\frac{d^{2} \pi^{*}}{d \rho^{2}} & =f^{\prime}\left(L^{*}\right) \frac{d L^{*}}{d \rho}>0
\end{aligned}
$$

where (7) uses the envelope theorem and the inequality in (8) is implied by the differential of (3) and the strict concavity of the production function. Hence, the profit function is an increasing and strictly convex function of the net price. However, the effect on $\rho$ arising from changes in $c$ will generally differ between the two regimes, due to the lack of deductibility of costs under presumptive taxation. To consider this relationship, rewrite the optimized profit function directly as a function of $c, \pi^{*}(c)$, and calculate its derivatives, as follows:

$$
\begin{aligned}
\frac{d \pi^{*}}{d c} & =\frac{d \pi^{*}}{d \rho} \frac{d \rho}{d c}=f\left(L^{*}\right) \frac{d \rho}{d c}<0 \\
\frac{d^{2} \pi^{*}}{d c^{2}} & =\frac{d^{2} \pi^{*}}{d \rho^{2}}\left(\frac{d \rho}{d c}\right)^{2}>0
\end{aligned}
$$

\footnotetext{
${ }^{7}$ An alternative assumption would be that the compliance cost is escaped when the firm chooses $L=0$. This would introduce a kink in the profit function of firms in the regular regime. However, the alternative assumption does not affect our findings on the optimal policies.
} 
where the linearity of the tax systems $\left(d^{2} \rho / d c^{2}=0\right)$ is used in deriving (10) and the relationship between cost and the net price $(d \rho / d c)$ is given by

$$
\begin{array}{lr}
\frac{d p^{P}}{d c}=-1 & \text { in the presumptive regime } \\
\frac{d p^{R}}{d c}=-\left(1-t^{c}\right) & \text { in the regular regime }
\end{array}
$$

The signs of the derivatives (9) and (10) follow from (7)-(8) and (11)-(12). Now consider the effect of the sales threshold, whereby firms face the presumptive tax only if their sales are below the threshold. It may cause some firms to achieve a constrained profit maximum by producing just below the threshold (but arbitrarily close to $\bar{Z}$ ) while facing the presumptive tax, or producing exactly at the threshold while facing the regular tax. We examine these situations later.

On the demand side, for simplicity, all individuals are assumed to have identical quasi-linear preferences, defined over the two final goods, with all income effects attached to the informalsector good. Since $p$ is fixed on world markets, individual demand for the formal-sector good $x(p)$ is independent of tax policy. Tax revenues, net of administrative costs in the case of the regular regime, are used to pay for public expenditure $G$, which is assumed to generate a constant marginal utility, $\delta>1 .^{8}$ An individual's indirect utility is then of the form $v(p)+\pi+\delta G$, where $v(p)$ is a constant that is independent of tax policy. If the tax payment of a type- $c$ individual net of any administration cost is denoted by $g(c)$, then the objective function of a utilitarian government can be represented by an expectation on the unit continuum for $c:^{9}$

$$
S W=E[v(p)+\pi(c)+\delta(g(c))]
$$

The model delivers optimal values for $t, t^{c}$ and $\bar{Z}$ simultaneously. We shall also consider how $t$ and $\bar{Z}$ should vary with the regular regime tax rate $t^{c}$, taking the latter variable as exogenous. This will allow us to comment on optimal reforms to a presumptive regime when the corporate income tax rate is taken as a given, but not necessarily at its optimal value; such partial reforms appear common in practice. Before proceeding to an analysis of the optimal threshold, it is interesting to contrast the presumptive and regular tax regimes, if all firms were placed in a single tax regime.

\section{COMPARING THE PRESUMPTIVE AND REgUlAR REgIMES}

We first consider the simple case in which all firms are placed in a single fiscal regime. The comparison is useful for identifying the benefits and costs of each type of tax. Observe that, if there were no variation in the unit cost $c$ across firms (i.e., if $H(c)$ were a degenerate distribu-

\footnotetext{
${ }^{8}$ In equilibrium, the marginal cost of public funds will be identical to the marginal utility of public spending.

${ }^{9}$ The expectation will consist of sets of integrals, corresponding to segments of firms in the regular regime and segments of firms in the presumptive regime.
} 
tion), then, for any value of $t^{c}$, there would be an equivalent value of $t$, such that $p^{P}=p^{R}$ and $L^{P^{*}}=L^{R^{*}}$. In that case, clearly the presumptive regime would dominate the regular regime, because of the compliance and administrative costs associated with the regular regime. However, when there is dispersion in the unit costs, there can be no value of $t$ that is equivalent to $t^{c}$ for every firm. Thus, as a result of the nondeductibility of costs in the presumptive regime, the output of many firms in the presumptive regime will be distorted, which results in a loss of social welfare. ${ }^{10}$ These observations are illustrated with the square root production function $f(L)=L^{1 / 2}$, which allows us to solve explicitly for the optimal tax rate in each regime and to show how welfare in the presumptive regime is a decreasing function of the variance of unit costs.

\section{A. All firms are in the regular regime}

With a square root production function and all firms placed in the regular regime, individual firms' profits and net tax payments, along with social welfare, are given by the expressions:

$$
\begin{aligned}
\pi^{R}(c) & =\left(\frac{1}{4 w}\right)\left(p^{R}\right)^{2}+w-\Gamma \\
g^{R}(c) & =t^{c}(p-c)\left(\frac{1}{2 w}\right)\left(p^{R}\right)^{2}-A \\
S W^{R} & =v(p)+\frac{1}{4 w} E\left(\left[\left(1-t^{c}\right)(p-c)\right]^{2}\right) \\
& +\delta \frac{1}{2 w} t^{c} E\left[(p-c)\left(1-t^{c}\right)(p-c)\right]+w-(\Gamma+\delta A)
\end{aligned}
$$

From the first- and second-order conditions for welfare maximization, we obtain the optimal tax rate in the regular regime, $t^{c *}$.

Lemma 1. The optimal tax rate in the regular regime is an increasing function of the marginal value of public funds and is independent of the distribution of unit costs. It is given by

$$
t^{c *}=\frac{\delta-1}{2 \delta-1}
$$

\footnotetext{
${ }^{10}$ This distortion compounds the distortion already present in either regime, due to the nondeductibility of the opportunity cost $w$ of $L$ supplied to the formal sector.
} 


\section{B. All firms in the presumptive regime}

When all firms are placed in the presumptive regime, the solutions for the same variables as above are:

$$
\begin{aligned}
\pi^{P}(c) & =\left(\frac{1}{4 w}\right)\left(p^{P}\right)^{2}+w \\
g^{P}(c) & =\left(\frac{t p}{2 w}\right)((1-t) p-c) \\
S W^{P} & =v(p)+\frac{1}{4 w} E\left([(1-t) p-c]^{2}\right)+\delta \frac{t p}{2 w} E[(1-t) p-c]+w
\end{aligned}
$$

Maximizing $S W^{P}$ with respect to $t$ yields the optimal presumptive tax rate, $t^{*}$.

Lemma 2. The optimal tax rate in the presumptive regime is an increasing function of the average profit margin of the sector and is smaller than the optimal tax rate in the regular regime. It is given by

$$
\begin{aligned}
t^{\star} & =\left(\frac{\delta-1}{2 \delta-1}\right)\left(\frac{p-E(c)}{p}\right) \\
& =t^{c *}\left(1-\frac{E(c)}{p}\right)
\end{aligned}
$$

The average profit margin is $(p-E(c)) / p$. The last equation implies that $0<t^{*}<t^{c *}$, since $p>E(c){ }^{11}$

\section{Comparison of welfare between the assigned regimes}

Substituting the optimal tax rates $t^{c *}$ and $t^{*}$ into (16) and (19), respectively, yields the maximized social welfare functions. The difference between the maximized values of $S W^{R}$ and $S W^{P}$ is given by following proposition.

Proposition 1. With a square root production function, the difference between social welfare in the regular regime and the presumptive regime is increasing in the variance of the unit costs $\sigma^{2}$, but decreasing in both the fixed compliance and administrative costs. Depending on these two forces, either regime could be optimal, if only one regime is possible and tax rates are linear. The welfare difference is given by

$$
S W^{R}-S W^{P}=-(\Gamma+\delta A)+\frac{1}{4 w} \frac{(\delta-1)^{2}}{(2 \delta-1)} \sigma^{2}
$$

\footnotetext{
${ }^{11} \mathrm{We}$ are assuming here interior solutions for $L$ for all firms, which is readily satisfied if $p$ is large enough, so that no firm faces a negative net price at $t^{*}$.
} 
Hence, the presumptive regime works best when there is little dispersion in the unit costs of firms in the presumptive regime, or, more generally speaking, in their profit margins. This observation can justify the common practice of categorizing firms in the presumptive regime by their types of economic activities and applying different tax rates to each category. Doing so reduces the variance of costs in each category, but it also makes the tax system more complex and may increase the cost of administering it. ${ }^{12}$

\section{Presumptive Regime With a sales threshold}

We now analyze the tax structure in which only firms with sales below some threshold $\bar{Z}$ are subjected to the presumptive regime, while firms with sales at or above $\bar{Z}$ are obliged to be in the regular regime. We proceed by characterizing the private sector equilibrium for an arbitrary policy triplet $\left\{t, t^{c}, \bar{Z}\right\}$, including which regime each firm faces, subject to the constraint imposed by the threshold. This is accomplished in several steps. We calculate the desired sales levels of firms at each tax rate, $t^{c}$ and $t$, and compare these outcomes with the turnover threshold, $\bar{Z}$, to characterize the choices effectively available to each firm. Comparisons of profit under the alternatives then determine each firm's optimal production decision. Thus, given the tax policy and the resulting market equilibrium, social welfare can be computed and the government, proceeding in this manner, searches for a global optimum. Of particular interest in the characterization of the behavior of firms is the possibility that some will "bunch" at, or just below, the sales threshold.

\section{A. Partitioning the distribution of firms}

To analyze the effect of the threshold on the behavior of firms, according to their unit costs, it is convenient to transform the profit function to express it in terms of sales. That is, maximizing (1) by choosing $L$ is equivalent to choosing $Z$ to maximize

$$
\pi(Z, \rho) \equiv \rho \frac{Z}{p}+w\left[1-f^{-1}\left(\frac{Z}{p}\right)\right]-I^{R} \Gamma
$$

in which $Z=p f(L)$ and $f^{-1}(Z / p)=L$ is the inverse of the production function. The desired sales level $Z(\rho) \equiv Z^{*}$ solves the first-order condition

$$
\frac{d \pi(Z, \rho)}{d Z}=\frac{\rho}{p}-\frac{w}{p f^{\prime}\left(f^{-1}\left(Z^{*} / p\right)\right)}=0
$$

\footnotetext{
${ }^{12}$ It is worth noting that the Keen and Mintz (2004) model of the optimal VAT, where all firms have the same input cost but differ in terms of productivity, is unsuitable for analyzing the questions addressed in our paper. Since every firm in their model has an identical unit cost, $p^{P}$ will be the same for every firm. Given $t^{c}$, a unique value of $t$ exists that makes $p^{P}=p^{R}$ for every firm. Thus the presumptive regime must dominate the regular regime, due to the fixed costs associated with the regular regime.
} 
Differentiating (22) and using the properties of inverse functions, the desired sales function is decreasing in the unit cost $c$ :

$$
\frac{d Z(\rho)}{d c}=\frac{d Z}{d \rho} \frac{d \rho}{d c}=-\frac{p}{w} \frac{\left(f^{\prime}\right)^{3}}{f^{\prime \prime}} \frac{d \rho}{d c}<0
$$

since $\frac{d \rho}{d c}<0$ and $f^{\prime \prime}<0$. A simple illustration of the desired sales curves and profit functions is provided by the square root production function $f(L)=L^{1 / 2}$ :

$$
Z(\rho)=\frac{p}{2 w} \rho
$$

and

$$
\pi(\rho)=\frac{\rho^{2}}{4 w}+w-I^{R} \Gamma
$$

Since $\rho$ is a linear function of $c$ and from (24) $Z(\rho)$ is itself linear in $\rho$, desired sales $Z(c)$ is linear in $c$ :

$$
\begin{aligned}
& Z^{R}(c)=\frac{p}{2 w}\left[\left(1-t^{c}\right)(p-c)\right] \\
& Z^{P}(c)=\frac{p}{2 w}[(1-t) p-c]
\end{aligned}
$$

The desired sales functions characterized by (22) and illustrated with (26)-(27) can be used to construct four mutually exclusive sets of unit costs that exhaust the domain of $H(c)$. These sets are determined by whether the desired sales level of a given firm with unit cost $c$ is below or above the threshold $\bar{Z}$. We will say that a firm is "constrained" by the threshold, if its desired turnover, when facing the presumptive tax, exceeds the threshold permitted for firms in the presumptive regime; or, if its desired turnover, when facing the regular tax regime, is below the threshold. Given any policy $\left\{t, t^{c}, \bar{Z}\right\}$, the four sets are

1. $Z^{P}(c) \geq \bar{Z}$ and $Z^{R}(c) \geq \bar{Z}$

(Only firms in the presumptive regime are constrained)

Define the set $S_{1}(c)=\left\{c \mid Z^{P}(c) \geq \bar{Z}\right.$ and $\left.Z^{R}(c) \geq \bar{Z}\right\}$

2. $Z^{P}(c) \geq \bar{Z}$ and $Z^{R}(c)<\bar{Z}$

(Firms are constrained in both regimes)

Define the set $S_{2}(c)=\left\{c \mid Z^{P}(c) \geq \bar{Z}\right.$ and $\left.Z^{R}(c)<\bar{Z}\right\}$

3. $Z^{P}(c)<\bar{Z}$ and $Z^{R}(c) \geq \bar{Z}$

(Firms are unconstrained in both regimes)

Define the set $S_{3}(c)=\left\{c \mid Z^{P}(c)<\bar{Z}\right.$ and $\left.Z^{R}(c) \geq \bar{Z}\right\}$

4. $Z^{P}(c)<\bar{Z}$ and $Z^{R}(c)<\bar{Z}$

(Only firms in the regular regime are constrained)

Define the set $S_{4}(c)=\left\{c \mid Z^{P}(c)<\bar{Z}\right.$ and $\left.Z^{R}(c)<\bar{Z}\right\}$ 


\section{B. Constructing the sets using sales diagrams}

The two curves described by (22) for $Z^{R}$ and $Z^{P}$ can be depicted on the same diagram, together with an arbitrary sales threshold $\bar{Z}$, with $c$ on the horizontal axis, in order to determine which firms are constrained by the threshold. The slopes and intercepts of $Z^{R}$ and $Z^{P}$ will depend on the (arbitrary) values of $t^{c}$ and $t$. The sales threshold is a horizontal line. We illustrate the procedure in Figure 1 using the linear case of (26) and (27), which cross where $p^{R}(c)=p^{P}(c)$, i.e., at $\hat{c}=\frac{\left(t^{c}-t\right) p}{t^{c}}$. Let $\hat{Z}=Z^{R}(\hat{c})=Z^{P}(\hat{c})$. Figure 1 depicts a situation where $Z^{R}$ has a lower intercept than $Z^{P}$ (corresponding to $t^{c}>t$ ) and the lines cross in the interior at $\hat{c}>0$ with the threshold $\bar{Z}>\hat{Z}$ (Case A). $Z^{R}$ is necessarily shallower than $Z^{P}$ in the linear case since $t^{c}<1$. In contrast, Figure 2 shows $\bar{Z}<\hat{Z}$ (Case B). In both figures, define $c^{\prime}$ by $Z^{P}\left(c^{\prime}\right)=\bar{Z}$ and $c^{\prime \prime}$ by $Z^{R}\left(c^{\prime \prime}\right)=\bar{Z}$. Similarly, the values of $c^{\prime}$ and $c^{\prime \prime}$ can be constructed for the cases where $Z^{R}$ has a higher intercept than $Z^{P}$ (corresponding to $t^{c}<t$ ) or the lines do not intersect in the interior of the space. We omit these analyses for the sake of brevity.

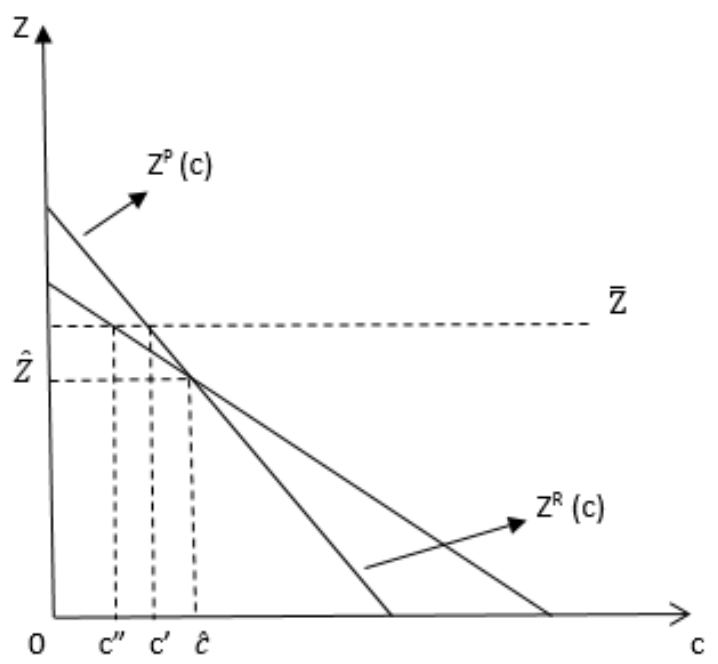

Figure 1. Case A

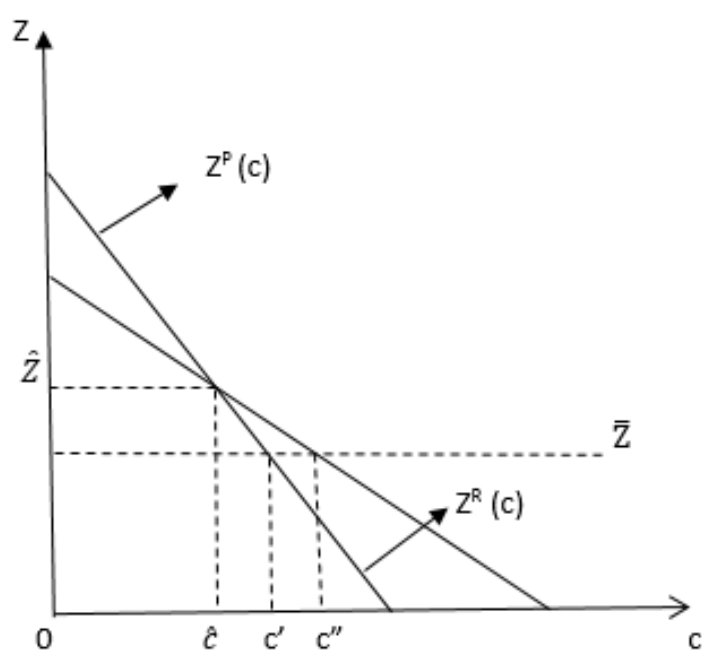

Figure 2. Case B

In Figure 1 , it can be seen that firms in the segment $\left[0, c^{\prime \prime}\right)$ would, if they are in the regular regime with the given tax rate $t^{c}$, desire a level of sales exceeding the threshold $\bar{Z}$. Hence, their optimal sales in the regular regime is unconstrained by the threshold. However, firms $\left[c^{\prime \prime}, 1\right]$ are constrained in the regular regime, in that their preferred sales level is below the threshold. In the presumptive regime, the segment $\left[0, c^{\prime}\right]$ is constrained by the threshold, because the threshold level of sales is inferior to their preferred sales level when facing the given presumptive tax rate $t$; firms in $\left[c^{\prime}, 1\right]$ are unconstrained in the presumptive regime, because their preferred level of sales is below the threshold. In Figure 2, the situation is slightly different, because $c^{\prime \prime}$ lies to the right of $c^{\prime}$. We have 
- Case A: shown in Figure $1 \Rightarrow$ if $\bar{Z} \geq \hat{Z}$, there is $0<c^{\prime \prime} \leq c^{\prime} \leq \hat{c}$

- Case B: shown in Figure $2 \Rightarrow$ if $\bar{Z}<\hat{Z}$, there is $0<\hat{c}<c^{\prime}<c^{\prime \prime}$

From the discussion of Figure 1, the sets $S_{1}$ to $S_{4}$ corresponding to Case A are given by

1. $S_{1}(c)=\left\{c: c \in\left[0, c^{\prime \prime}\right)\right\}$

2. $S_{2}(c)=\left\{c: c \in\left[c^{\prime \prime}, c^{\prime}\right)\right\}$

3. $S_{3}(c)=\emptyset$

4. $S_{4}(c)=\left\{c: c \in\left[c^{\prime}, 1\right]\right\}$

Similarly, from Figure 2, the sets in Case B are given by

1. $S_{1}(c)=\left\{c: c \in\left[0, c^{\prime}\right)\right\}$

2. $S_{2}(c)=\emptyset$

3. $S_{3}(c)=\left\{c: c \in\left[c^{\prime}, c^{\prime \prime}\right]\right\}$

4. $S_{4}(c)=\left\{c: c \in\left(c^{\prime \prime}, 1\right]\right\}$

Note that, in each case, the union of the four sets equals $[0,1]$. With a given sales threshold, there are four types of profit functions associated with a firm's choice of tax regime:

1. Unconstrained in presumptive regime: $\pi^{P}\left(p^{P}\right)=p^{P} \frac{Z\left(p^{P}\right)}{p}+w\left[1-f^{-1}\left(\frac{Z\left(p^{P}\right)}{p}\right)\right]$

2. Constrained in presumptive regime: $\pi^{B}\left(p^{P}\right)=p^{P} \frac{\bar{Z}}{p}+w(1-\mu(\bar{Z}))$

3. Unconstrained in regular regime: $\pi^{R}\left(p^{R}\right)=p^{R} \frac{Z\left(p^{R}\right)}{p}+w\left[1-f^{-1}\left(\frac{Z\left(p^{R}\right)}{p}\right)\right]-\Gamma$

4. Constrained in regular regime: $\pi^{A}\left(p^{R}\right)=p^{R} \frac{\bar{Z}}{p}+w(1-\mu(\bar{Z}))-\Gamma$

where $\mu=f^{-1}\left(\frac{\bar{Z}}{p}\right)$ is the labor supply that makes sales just equal to the threshold. The profit $\pi^{B}\left(p^{P}\right)$ corresponds to firms that "bunch" just below the threshold. If their sales were any higher, they would have to switch to the regular regime. Similarly, $\pi^{A}\left(p^{R}\right)$ is the profit of firms in the regular regime, who bunch at the threshold. If their sales were any lower, they would be obliged to face the presumptive tax regime. ${ }^{13}$ Each firm compares the profits it can earn from alternative choices of regime and sales level. This is done with profit-difference functions, as follows.

\footnotetext{
${ }^{13}$ All firms that are restricted from achieving their desired sales level by the threshold would choose the threshold level of sales as their constrained optimum-hence the notion of bunching.
} 
1. For firms in $S_{1}: D_{1}(c)=\pi^{R}(c)-\pi^{B}(c)$

Assume that firms choose the regular regime if and only if $D_{1}(c)>0$.

2. For firms in $S_{2}: D_{2}(c)=\pi^{A}(c)-\pi^{B}(c)$

Assume that firms bunch at the threshold if and only if $D_{2}(c)>0$.

3. For firms in $S_{3}: D_{3}(c)=\pi^{R}(c)-\pi^{P}(c)$

Assume that firms choose the regular regime if and only if $D_{3}(c)>0$.

4. For firms in $S_{4}: D_{4}(c)=\pi^{A}(c)-\pi^{P}(c)$

Assume that firms bunch at the threshold if and only if $D_{4}(c)>0$.

The roots of the profit-difference curves partition the cost space into firms that are better off under one one tax regime or the other. Thus the roots identify every firm's optimal choice of sales and hence the fiscal regime each is subjected to, given the tax policies $\left\{t, t^{c}, \bar{Z}\right\}$ and the compliance cost $\Gamma$.

Proposition 2. The profit-difference curves have the following characteristics.

1. The graph of $D_{1}(c)$ is strictly convex and has at most two real roots. If the roots are imaginary, then all firms in $S_{1}$ choose the regular regime.

2. The graph of $D_{2}(c)$ is linear and is positively sloped for any $t^{c}>0$. Let $c^{*}$ denote its single root. Firms in $S_{2}$ with $c^{*} \leq c \leq 1$ choose to bunch at the threshold. If $c^{*}>1$, then all firms in $S_{2}$ choose to bunch just below the threshold.

3. The graph of $D_{3}(c)$ is strictly quasi-concave and has at most two real roots, if $3\left(f^{\prime \prime}\right)^{2}-$ $f^{\prime} f^{\prime \prime \prime}$ is positive for all $L>0$. If the roots are imaginary, then all firms in $S_{3}$ choose the presumptive regime. ${ }^{14}$

4. The graph of $D_{4}(c)$ is strictly quasi-concave and has at most two real roots. If the roots are imaginary, then all firms in $S_{4}$ choose the presumptive regime.

The quasi-concavity or convexity of the profit-difference curves (except for $D_{2}$ ) can give rise to situations where the curves have a hump-shape or an inverted hump-shape, respectively. Take, for example, the case of $D_{3}(c)=\pi^{R}(c)-\pi^{P}(c)$. It is an increasing function at low values of $c$ if $d D_{3}(0) / d c>0 .{ }^{15}$ However, it eventually it starts decreasing, because $\pi^{P}$ flattens as $p^{P}$ approaches 0; meanwhile, $\pi^{R}$ continues to decline with $c$, since $p^{R}>0$ and $d p^{R} / d c<0$ for all $c$. Thus, $D_{3}$ would initially rise, reach a peak, and then fall, yielding two possible real roots for $D_{3}(c)=0$.

\footnotetext{
${ }^{14}$ The sufficiency condition is weaker than requiring $f(L(\rho))$ to be strictly concave in $\rho$ (i.e., $2\left(f^{\prime \prime}\right)^{2}-f^{\prime} f^{\prime \prime \prime}>$ 0 ), which is satisfied by standard production functions, such as the exponential, the logarithmic, and the quadratic forms of $f(L)$.

${ }^{15}$ When $f(L)=L^{\alpha}$, the parametric condition for $d D_{3}(0) / d c>0$ is $\left(1-t^{c}\right)<(1-t)^{\alpha}$.
} 
Each of the profit-difference curves can be superimposed on the sets $S_{1}, S_{2}, S_{3}$, and $S_{4}$, with the roots of the functions used to characterize the equilibrium choice of each firm $c \in[0,1]$. To illustrate the approach, consider again the case of $D_{3}=\pi^{R}-\pi^{P}$ and assume it has a humpshape. Define $c_{l}$ and $c_{h}$ as the lower and upper roots of $D(c)$, respectively.

Proposition 3. If the profit-difference curve $\pi^{R}(c)-\pi^{P}(c)$ is hump-shaped with real roots $c_{l}$ and $c_{h}$, then

1. $\forall c \in\left[0, c_{l}\right), \pi^{P}>\pi^{R} \Rightarrow$ firms are better off in the presumptive regime

2. $\forall c \in\left[c_{l}, c_{h}\right], \pi^{R} \geq \pi^{P} \Rightarrow$ firms are better off in the regular regime

3. $\forall c \in\left(c_{h}, 1\right], \pi^{P}>\pi^{R} \Rightarrow$ firms are better off in the presumptive regime

To ensure that the roots are confined to the unit interval, in the statements above, for $i=$ $\{l, h\}$, if $c_{i}<0$, replace $c_{i}$ with $c_{i}=0$, while if $c_{i}>1$, replace it with $c_{i}=1$.

The following lemma shows how to apply these observations.

Lemma 3. Define $c^{\prime}$ by $Z^{P}\left(c^{\prime}\right)=\bar{Z}$ and $c^{\prime \prime}$ by $Z^{R}\left(c^{\prime \prime}\right)=\bar{Z}$ and suppose that tax policy $\left\{t, t^{c}, \bar{Z}\right\}$ generates Case B in Figure 2. Then the behavior of the firms in the interval $S_{3}=\left[c^{\prime}, c^{\prime \prime}\right]$ is characterized by the intersection of $S_{3}$ and each of the three intervals described in proposition 3.

The proposition records an interesting and novel observation: both the relatively low-cost and the relatively high-cost firms can prefer the presumptive regime, with only the middle-cost firms preferring the regular regime. Intuitively, non-deductibility is unimportant for low-cost firms and hence they will favor the presumptive regime, either to avoid the compliance cost of the regular regime or because $t^{c}>t$. At the other end of the cost spectrum, high-cost firms have relatively small operating profits and so they will tend to prefer the presumptive regime to avoid the compliance cost. It is the middle cost firms that are confronted with an important tradeoff between the nondeductibility of costs in the presumptive regime and the cost of compliance in the regular regime. If, instead of having a hump-shape, the profit-difference curve is monotonically decreasing, then there will be a single root, which will again partition the firms in an obvious way. In general, it will be clear from the graphs of the various profit-difference curves how firms in each of the different segments of $[0,1]$ behave (in terms of labor supply and hence of sales) for any given tax policy.

To illustrate further, consider the case of $f(L)=L^{1 / 2}$. The profit-difference $D_{3}(c)$ is then a quadratic function, over the interval of costs for which $p^{P}(c) \geq 0$ :

$$
\pi^{R}-\pi^{P}=\frac{1}{4 w}\left[\left(1-t^{c}\right)^{2}-1\right] c^{2}+\frac{p}{2 w}\left[(1-t)-\left(1-t^{c}\right)^{2}\right] c+\left\{\frac{p^{2}}{4 w}\left[\left(1-t^{c}\right)^{2}-(1-t)^{2}\right]-\Gamma\right\}
$$


For the interval of costs for which $p^{P}(c)<0$ and hence $\pi^{P}=w$, the profit-difference curve in that case is simply

$$
\pi^{R}-\pi^{P}=\frac{1}{4 w}\left[\left(1-t^{c}\right)(p-c)\right]^{2}-\Gamma
$$

The roots of (28) are

$$
c=\frac{p\left[(1-t)-\left(1-t^{c}\right)^{2}\right] \pm p \sqrt{t^{2}\left(1-t^{c}\right)^{2}-\frac{4 w}{p^{2}}\left[1-\left(1-t^{c}\right)^{2}\right] \Gamma}}{1-\left(1-t^{c}\right)^{2}}
$$

Real roots exist if and only if $\Gamma \leq \Gamma^{\prime}$, where

$$
\Gamma^{\prime}=\frac{p^{2}}{4 w}\left(\frac{t^{2}\left(1-t^{c}\right)^{2}}{1-\left(1-t^{c}\right)^{2}}\right)
$$

Suppose the compliance cost is $\Gamma=0$. The two roots in (30) become:

$$
c_{l}=\frac{\left(t^{c}-t\right) p}{t^{c}} ; c_{h}=\frac{\left(2-t^{c}-t\right) p}{2-t^{c}}
$$

The upper root $c_{h}$ is inadmissible because $p^{P}\left(c_{h}\right)<0 .{ }^{16}$ If $t<t^{c}$, then $c_{l}>0$ and firms with $c \in\left[0, c_{l}\right)$ prefer the presumptive regime, while firms with $c \in\left[c_{l}, 1\right]$ prefer the regular regime (firm- $c_{l}$ is indifferent). If $t<t^{c}$ but $c_{l}>1$, then all firms prefer the presumptive regime. Finally, if $t \geq t^{c}$, then $c_{l} \leq 0$ and all firms (weakly) prefer the regular regime. For larger values of $\Gamma$, both $c_{l}$ and $c_{h}$ can be admissible roots of the profit-difference curve. Figure 3 (panels $a$ to $c$ ) provides graphs of the profit-difference curve $D_{3}(c)=\pi^{R}(c)-\pi^{P}(c)$ for different values of $\Gamma$. The inflexion point in each graph corresponds to the point at which $p^{P}(c)$ becomes negative, so the profit-difference curve equation switches from (28) to (29). In panel $a$, $\Gamma$ is small, so the only root for (28) is $c_{l}$; firms with unit costs exceeding $(1-t) p$ will switch to a corner solution, in which $L^{*}=0$ and $\pi^{P}$ becomes a constant equal to $w$. For larger values of $\Gamma$, both roots of (28) become admissible, as illustrated in panel $b$. Finally, in panel $c, \Gamma$ is so large that there are no real roots for $D(c)$ - every firm prefers to be subjected to the presumptive regime instead of the regular regime.

Figures 4 and 5 illustrate how the four $S$ sets and the profit-difference curves are combined to determine the market equilibrium. The sets $S_{1}$ to $S_{4}$ partition the cost space $[0,1]$ and the corresponding profit-difference curves $D_{1}$ to $D_{4}$ determine the behaviors of the firms in each segment, depending on the values of the roots. Figure 4 shows the Case A configuration of $Z^{P}(c), Z^{R}(c)$ and $\bar{Z}$ such that $\bar{Z} \geq \hat{Z}$ and $0<c^{\prime \prime} \leq c^{\prime} \leq \hat{c}$, as previously illustrated in Figure 1. Figure 5 shows the Case $\mathrm{B}$ configuration, where $\bar{Z}<\hat{Z}$ and $0<\hat{c}<c^{\prime}<c^{\prime \prime}$, as previously illustrated in Figure 2. The bottom portions of Figure 4 and Figure 5 provide graphs of the profit-difference curves for the sets $S_{1}(c), S_{2}(c), S_{3}(c)$, and $S_{4}(c)$, associated with Case $\mathrm{A}$ and Case B, respectively. Observe that the profit-difference curves corresponding to each

\footnotetext{
${ }^{16}$ In that case, the admissible upper root is obtained from (29), which is $c_{h}=p-2(w \Gamma)^{1 / 2} /\left(1-t^{c}\right)$.
} 


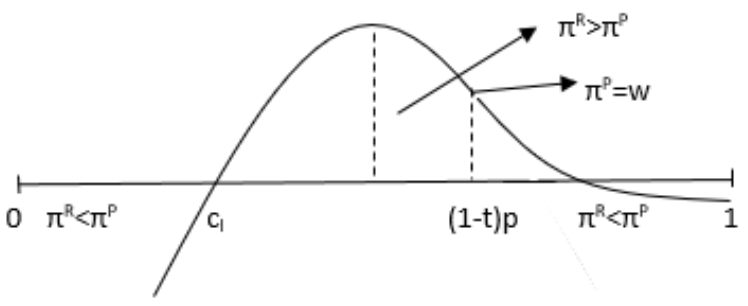

(a) Case with $\Gamma \in\left[0, \Gamma^{\prime \prime}\right)$

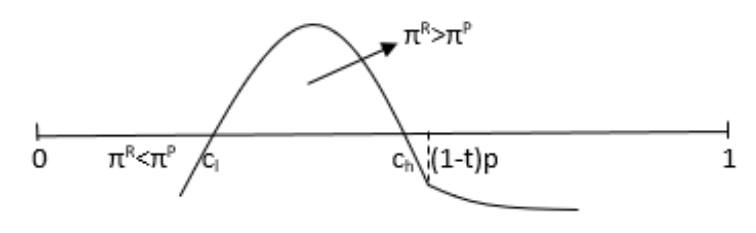

(b) Case with $\Gamma \in\left[\Gamma^{\prime \prime}, \Gamma^{\prime}\right]$

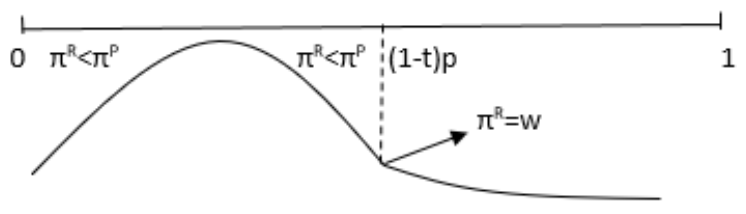

(c) Case with $\Gamma \in\left(\Gamma^{\prime}, \infty\right)$

Figure 3. $D(c)=\pi^{R}(c)-\pi^{P}(c)$ with different scales of $\Gamma$

segment can be "stitched" together to form a continuous curve. To see this, recall that $S_{3}$ is empty in Case A, so $D_{3}$ becomes irrelevant. The curves $D_{1}$ and $D_{2}$ are therefore joined, using the fact that $\pi^{R}=\pi^{A}$ at the unique cost at which the desired sales curve equals the threshold, $Z^{R}\left(c^{\prime \prime}\right)=\bar{Z}$. Similarly, $D_{2}$ is joined to $D_{4}$ at the cost level at which $\pi^{P}=\pi^{B}\left(c^{\prime}\right)$. In Case B, $S_{2}$ is empty and $D_{2}$ becomes irrelevant. Then, $D_{1}$ is joined to $D_{3}$ where $\pi^{P}=\pi^{B}\left(c^{\prime}\right)$ and $D_{3}$ is joined to $D_{4}$ where $\pi^{R}=\pi^{A}\left(c^{\prime \prime}\right)$. Thus, we can speak of an overall profit-difference curve as the outcome of joining the specific profit-difference curves over the $S_{1}, S_{2}, S_{3}$ and $S_{4}$ segments of the unit interval.

Figure 4 exhibits a unique root for $D_{1}(c)$ within the set of costs $S_{1}=\left[0, c^{\prime \prime}\right)$, indicated as $c_{1}$. In the segment $S_{2}=\left[c^{\prime \prime}, c^{\prime}\right)$, there are no real roots. In the segment $\left[c^{\prime}, 1\right]$, there are two admissible roots, labelled $c_{4}$ and $c_{5}$; hence, only the firms with unit costs $c_{4}<c<c_{5}$ prefer a sales level that puts them at the threshold for the regular regime, rather than in the presumptive regime. in Figure 5, there are two admissible roots in the segment $S_{1}=\left[0, c^{\prime}\right)$, shown as $c_{1}$ and $c_{2}$; thus, among these firms, the ones in the subintervals $\left[0, c_{1}\right)$ and $\left[c_{2}, c^{\prime}\right)$ prefer the regular regime, while the "intermediate" firms prefer to bunch just below the threshold. Figure 5 also shows that all firms in the set $S_{3}=\left[c^{\prime}, c^{\prime \prime}\right]$ choose the regular regime over the presumptive regime, while firms in the set $S_{4}=\left(c^{\prime \prime}, 1\right]$ bunch at the threshold. Thus, Figures 4 and 5 illustrate how, for a given tax policy, we can characterize the behavior of all of the firms to determine which tax regime each firm is subjected to in equilibrium. It is then straightforward to compute the social welfare value corresponding to the given tax policy. A global welfare optimum can be determined by performing a grid search across all combinations of $\left\{t^{c}, t, \bar{Z}\right\}$. 


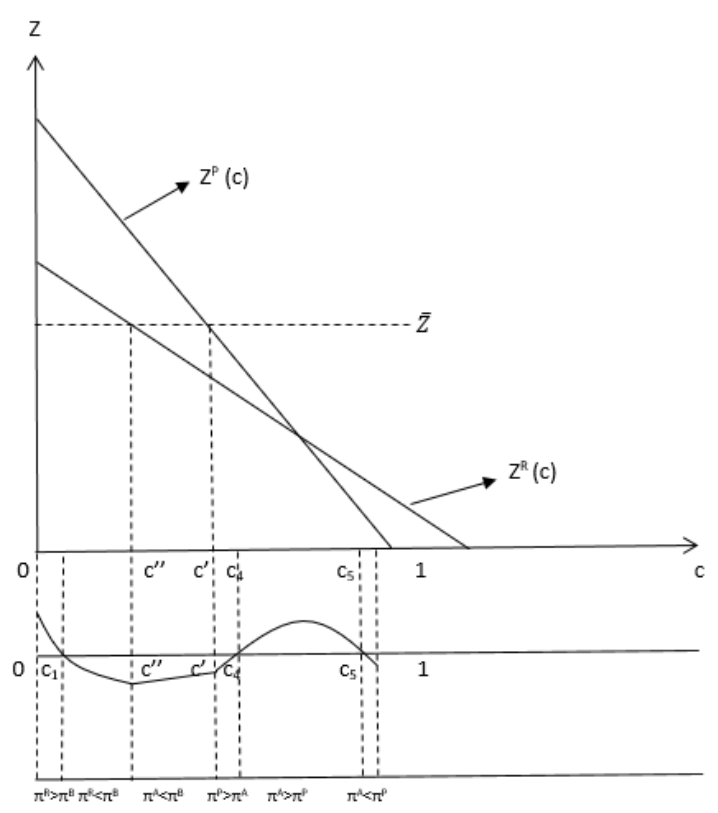

Figure 4. Case A

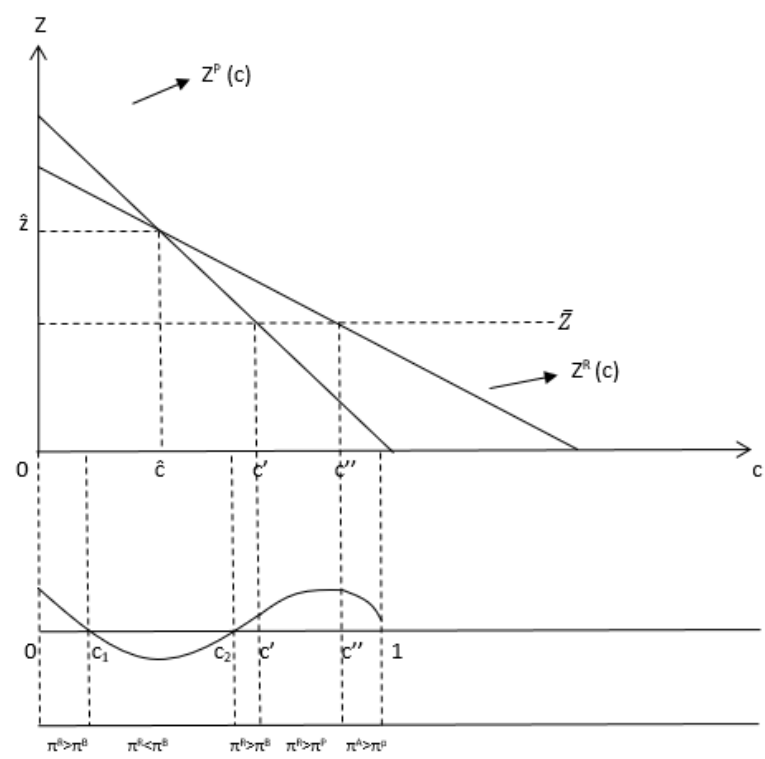

Figure 5. Case B

\section{Social Welfare OPTIMIZATION}

Due to the discontinuous nature of the private sector equilibria-i.e., the number of admissible roots can change as tax rates or the sales threshold change-using calculus to optimize the global value of social welfare is infeasible. However, it is possible to characterize the firstorder conditions for welfare maximization at an interior local optimum.

From our numerical simulations, it turns out that the globally optimal tax policy generates the configuration shown in Figure 6, which is analogous to Figure 5 in the previous section, except that there is now a single root, denoted by $c_{1}$, for the overall profit-difference curve. The welfare function in the neighborhood of this optimal policy can then be constructed using the variables $c^{\prime}$ and $c_{1}$ from Figure 6 as limits of integration. ${ }^{17}$ The aggregate net profit function

\footnotetext{
${ }^{17}$ Note that $c_{1}$ is the lower root of $\pi^{R}-\pi^{B}=0$, which determines which firms in the set $S_{1}$ for Case B will choose the regular regime versus bunching below the threshold. In Figure $6, S_{1} \equiv\left[0, c^{\prime}\right]=\left[0, c_{1}\right) \cup\left[c_{1}, c^{\prime}\right]$ and firms in $\left[0, c_{1}\right)$ are unconstrained in the regular regime, while those in $\left[c_{1}, c^{\prime}\right]$ choose to be constrained just below the threshold; the set $S_{2}$ is empty, while in $S_{3} \equiv\left[c^{\prime}, c^{\prime \prime}\right]$ and $S_{4} \equiv\left(c^{\prime \prime}, 1\right]$ all the firms prefer to be unconstrained by the threshold in the presumptive regime over any alternative behavior. The equilibrium depicted in Figure 6 can be referred to as R-B-P, meaning that relatively low-cost firms $\left(c \in\left[0, c_{1}\right)\right)$ are unconstrained in the regular regime (R), mid-cost firms $\left(c \in\left[c_{1}, c^{\prime}\right]\right)$ bunch just below the threshold $(\mathrm{B})$, while higher-cost firms $\left(c \in\left(c^{\prime}, 1\right]\right)$ are unconstrained in the presumptive regime $(\mathrm{P})$.
} 


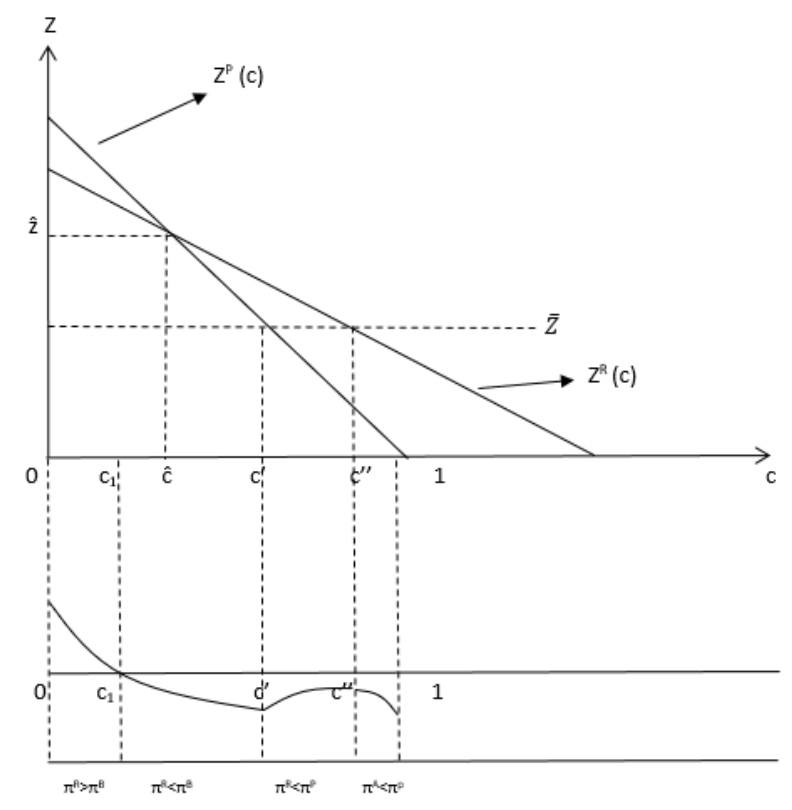

Figure 6. Figure from Simulation Results

is given by

$$
\begin{aligned}
\Pi\left(\bar{Z}, t, t^{c}\right) & =\int_{0}^{c_{1}}\left\{p^{R} f\left(L\left(p^{R}\right)\right)+w\left[1-L\left(p^{R}\right)\right]-\Gamma\right\} h(c) d c \\
& +\int_{c_{1}}^{c^{\prime}}\left\{p^{P} \frac{\bar{Z}}{p}+w[1-\mu(\bar{Z})]\right\} h(c) d c \\
& +\int_{c^{\prime}}^{1}\left\{p^{P} f\left(L\left(p^{P}\right)\right)+w\left[1-L\left(p^{P}\right)\right]\right\} h(c) d c
\end{aligned}
$$

where $\mu(\bar{Z})$ is the labor supply at which a firm's sales equals the threshold. The first term on the right-hand side of (33) is the net profit of firms in the regular regime; the second term is the net profit of firms just below the threshold; the third term is the net profit of firms unconstrained in the presumptive regime. Government spending is given by

$$
\begin{aligned}
G\left(\bar{Z}, t, t^{c}\right) & =\int_{0}^{c_{1}}\left[t^{c}(p-c) f\left(L\left(p^{R}\right)\right)-A\right] h(c) d c \\
& +\int_{c_{1}}^{c^{\prime}} t \bar{Z} h(c) d c \\
& +\int_{c^{\prime}}^{1} t p f\left(L\left(p^{P}\right)\right) h(c) d c
\end{aligned}
$$

The first term on the right-hand side of (34) is the tax revenues in the regular regime, net of administrative costs; the second term is the tax revenues collected from the firms just below the threshold; the third term is the revenue generated by firms in the presumptive regime that are unconstrained by the threshold. Social welfare can be written in terms of these aggregates 
as,

$$
S W=\Pi\left(\bar{Z}, t, t^{c}\right)+\delta G\left(\bar{Z}, t, t^{c}\right)+V(p)
$$

where $V(p)$ is the aggregate consumer surplus from sales in the formal sector, which is a constant and hence of no consequence for the welfare optimization. The first-order condition for welfare-maximization with respect to the threshold $\bar{Z}$ can be rearranged to obtain the following result.

Proposition 4. The optimal threshold is characterized by:

$$
\begin{aligned}
& \delta\left[\left(t^{c}\left(p-c_{1}\right) f\left(L\left(p^{R}\left(c_{1}\right)\right)\right)-A-t \bar{Z}\right)\right] h\left(c_{1}\right) \frac{d c_{1}}{d \bar{Z}} \times(-1) \\
= & \int_{c_{1}}^{c^{\prime}}\left[\frac{p^{P}}{p}-w \mu_{\bar{Z}}\right] h(c) d c+\delta t\left[H\left(c^{\prime}\right)-H\left(c_{1}\right)\right]
\end{aligned}
$$

where $\mu_{\bar{Z}} \equiv d \mu / d \bar{Z}$. The left-hand side of (36) (in absolute value) is the net effect along the extensive margin (EM) that results from raising the threshold by $\$ 1$, while the right-hand side is the net effect along the intensive margin (IM) of raising the threshold by $\$ 1$. At the optimum, the extensive and intensive margins are balanced. ${ }^{18}$ The extensive margin refers to the change in welfare arising from the relocation of some firms from the regular regime toward bunching just below the threshold in the presumptive regime. In contrast, the intensive margin refers to the change in welfare from the increased threshold, holding the mass of firms in each regime constant. Beginning with the extensive margin, on the left side of (36), the mass of firms moving from the regular regime to now bunching below the threshold is $h\left(c_{1}\right)\left(d c_{1} / d \bar{Z}\right)$, where $d c_{1} / d \bar{Z}$ is the leftward shift of $c_{1}$ in Figure 6 and $h\left(c_{1}\right)$ is the density of firms at $c_{1}{ }^{19}$ This shift in mass is multiplied by the total tax revenue change per affected firm: $t^{c}\left(p-c_{1}\right) f\left(L\left(p^{R}\left(c_{1}\right)\right)\right)-A$ is the tax revenue loss in the regular regime, net of savings of administrative costs, while $t \bar{Z}$ is the gain from the presumptive tax on each new "buncher." Turning to the intensive margin, the first term on the right side of (36) is positive and represents the gain in production efficiency: when the threshold is increased, firms that used to bunch below the threshold would expand their output. ${ }^{20}$ The second term is the extra tax revenue in the presumptive regime directly due to the higher threshold: every firm previously bunching in the presumptive regime (i.e., the mass of firms with unit costs between $c_{1}$ and $c^{\prime}$ )

\footnotetext{
${ }^{18}$ Letting $d S W / d \bar{Z}=E M+I M=0$, the optimum requires $-E M=I M$.

${ }^{19}$ Since firms constrained below the threshold desire to expand sales, their profits rise as $\bar{Z}$ is raised. At the same time, the profits of firms unconstrained in the regular regime are unaffected by the threshold. Consequently, $\pi^{R}(c)-\pi^{B}(c)$, which has an inverted hump-shape (i.e., a parabola that opens upward in the square root production function case), must sink at every $c$, as $\bar{Z}$ increases. $c_{1}$ is the lower root of the profit-difference curve $D_{1}$; hence, $d c_{1} / d \bar{Z}<0$.

${ }^{20}$ Recall that $\bar{Z}=p f(\mu(\bar{Z}))$ and hence $\mu_{\bar{Z}}=\frac{1}{p f^{\prime}}$. In equation (36), all firms with cost between $c_{1}$ and $c^{\prime}$ are constrained by the threshold and would choose, in its absence, to produce more. So, for them,
}

$$
p^{P} f^{\prime}-w>0
$$

and it follows, after substituting in the expression for $\mu_{\bar{Z}}$, that $\frac{p^{p}}{p}-w \mu_{\bar{Z}}>0$. 
pay an additional $t \times \$ 1$, with the increased tax revenues weighted by the marginal utility of public spending. ${ }^{21}$

The first-order condition for welfare with respect to the presumptive tax rate $t$ gives the following result. ${ }^{22}$

Proposition 5. The optimal t is characterized as:

$$
\begin{aligned}
& \delta\left[t^{c}\left(p-c_{1}\right) f\left(L\left(p^{R}\left(c_{1}\right)\right)\right)-A-t \bar{Z}\right] h\left(c_{1}\right) \frac{d c_{1}}{d t} \times(-1) \\
= & (\delta-1) \bar{Z}\left[H\left(c^{\prime}\right)-H\left(c_{1}\right)\right]+(\delta-1) \int_{c^{\prime}}^{1} p f\left(L\left(p^{P}\right)\right) h(c) d c \\
- & \delta \int_{c^{\prime}}^{1} t p^{2} f^{\prime} \frac{d L}{d p^{P}} h(c) d c
\end{aligned}
$$

The left side of (37) (in absolute value) is the effect along the extensive margin of increasing the presumptive tax rate $t$ and the right side is the effect along the intensive margin. When $t$ increases by $1 \%$, the mass $h\left(c_{1}\right) \frac{d c_{1}}{d t}$ of firms with $\operatorname{cost} c_{1}$, who previously stayed just below the threshold, would now move to the regular regime, ${ }^{23}$ resulting in a welfare change equal to $\delta$ times the net revenue gain in the regular regime, $t^{c}\left(p-c_{1}\right) f\left(L\left(p^{R}\left(c_{1}\right)\right)\right)-A$, minus the revenue loss from the former "bunchers," $t \bar{Z}$. As for intensive margin, the first pair of terms on the right-hand side of (37) gives the welfare change due to the increased revenues from both the bunchers and unconstrained firms in the presumptive regime, respectively, while the last term is the welfare loss from the lower tax revenues caused by the reduction in the output of the firms in the presumptive regime, ${ }^{24}$ as a result of the increased tax rate. In summary, Propositions 4 and 5 can provide guidance on tax reforms. Consider the impacts of slightly raising $t$ from a given level. The following effects must be considered.

1. The net revenue change from the firms switching to the regular regime.

2. The greater administrative costs generated by the firms switching to the regular regime.

3. The tax revenue gain from firms that remain in the presumptive regime.

4. The reduction in the output of firms in the presumptive regime.

\footnotetext{
${ }^{21}$ Note that the compliance cost, $\Gamma$, does not explicitly enter the social welfare first-order conditions, because the marginal firm, $c_{1}$, already balances the discontinuous gain in net profit in moving to the regular regime with the compliance cost incurred.

${ }^{22}$ For brevity, we omit from the discussion the first-order condition with respect to the regular tax rate $t^{c}$. Thus, the results can be interpreted as optimizing welfare by choosing $\bar{Z}$ and $t$ for a given value of $t^{c}$. The first-order condition with respect to $t^{c}$ is given in the appendix.

${ }^{23} \pi^{R}(c)-\pi^{B}(c)$ has an inverted hump shape and $\pi^{R}$ is independent of $t$, while $\pi^{B}$ is decreasing in $t$. Consequently, an increase in $t$ lifts the graph of the profit-difference curve, making $c_{1}$ shift to the right. Hence, $d c_{1} / d t>0$.

${ }^{24}$ The term, $-t p^{2} f^{\prime} \frac{d L}{d p^{P}}$, stems from $t p\left(f^{\prime} \frac{d L}{d p^{P}} \frac{d p^{P}}{d t}\right)$ with $\frac{d p^{P}}{d t}=-p$. It can also be written as the product of sales and the elasticity of output with respect to the presumptive tax rate: $Z^{P}\left(\frac{d f}{d t}\right)\left(\frac{t}{f}\right)$ where $Z^{P}=p f\left(L\left(p^{P}\right)\right)$.
} 
Table 2. Simulation Results

\begin{tabular}{|c|c|c|c|c|c|c|c|c|}
\hline Tax rate in the regular regime & $11.0 \%$ & $14.0 \%$ & $17.0 \%$ & $20.0 \%$ & $23.0 \%$ & $26.0 \%$ & $29.0 \%$ & \\
\hline Optimal tax rate in the presumptive regime & $6.00 \%$ & $4.40 \%$ & $2.40 \%$ & $2.60 \%$ & $2.80 \%$ & $3.10 \%$ & $6.00 \%$ & \\
\hline Optimal sales threshold ( $\$$ thousand) & 924 & 339 & 141 & 120 & 97 & 86 & 924 & \\
\hline Placement of firms & $\mathrm{P}$ & $R-A-P$ & $R-B-P$ & $R-B-P$ & $R-B-P$ & $R-B-P$ & $\mathrm{P}$ & \\
\hline Proportion of firms & $100 \%$ & $42 \%-14 \%-44 \%$ & $65 \%-9 \%-26 \%$ & $68 \%-8 \%-24 \%$ & $73 \%-6 \%-21 \%$ & $75 \%-4 \%-21 \%$ & $100 \%$ & \\
\hline Average value-added per firm & $1.26 \mathrm{E}+05$ & $1.27 \mathrm{E}+05$ & $1.23 \mathrm{E}+05$ & $1.23 \mathrm{E}+05$ & $1.16 \mathrm{E}+05$ & $1.12 \mathrm{E}+05$ & $1.26 \mathrm{E}+05$ & \\
\hline Average compliance cost / turnover & n.a. & $0.39 \%$ & $0.39 \%$ & $0.41 \%$ & $0.42 \%$ & $0.43 \%$ & n.a. & \\
\hline Compliance cost / turnover at the threshold & n.a. & $0.35 \%$ & $0.85 \%$ & $1.00 \%$ & $1.24 \%$ & $1.40 \%$ & n.a. & \\
\hline Social Welfare & 82185.22 & 82185.68 & 82476.49 & 82626.64 & 82611.02 & 82419.20 & 82185.22 & \\
\hline Comparative Statistics & $t^{c *}$ & $t^{*}$ & $\bar{Z}^{*}(\$$ thousand $)$ & Place of firms & Proportion of firms & $\begin{array}{l}\text { Average } \\
\text { value-added } \\
\text { per firm }\end{array}$ & $\begin{array}{l}\text { Average } \\
\text { compliance } \\
\text { cost / } \\
\text { turnover }\end{array}$ & $\begin{array}{l}\text { Compliance } \\
\text { cost / turnover } \\
\text { at the threshold }\end{array}$ \\
\hline $\begin{array}{l}\text { Baseline: } \Gamma=1200, A=240, \delta=1.3 \text {, } \\
\alpha=0.45 \text { and } \beta=800\end{array}$ & $20.9 \%$ & $2.7 \%$ & 113 & $R-B-P$ & $70 \%-7 \%-23 \%$ & $1.18 \mathrm{E}+05$ & $0.41 \%$ & $1.06 \%$ \\
\hline Case 1. $\Gamma=1300, A=260$ & $21.1 \%$ & $2.8 \%$ & 112 & $R-B-P$ & $70 \%-7 \%-23 \%$ & $1.18 \mathrm{E}+05$ & $0.45 \%$ & $1.16 \%$ \\
\hline Case 2. $\delta=1.35$ & $23.1 \%$ & $2.8 \%$ & 99 & $R-B-P$ & $72 \%-7 \%-21 \%$ & $1.16 \mathrm{E}+05$ & $0.42 \%$ & $1.21 \%$ \\
\hline Case 3. $\beta=810$ & $21.3 \%$ & $2.7 \%$ & 114 & $R-B-P$ & $70 \%-8 \%-22 \%$ & $1.20 \mathrm{E}+05$ & $0.40 \%$ & $1.05 \%$ \\
\hline
\end{tabular}

The weight $\delta$ is applied to the net change in tax revenues arising from shifts in the equilibrium allocation of firms or from changes in their output, while the weight $(\delta-1)$ is applied when firms pay more of their current profits as tax revenues. The proportion of firms switching from bunching just below the threshold to entering the regular regime (point 1) and the efficiency loss from raising the presumptive tax rate (point 4) are empirical matters.

\section{NUMERICAL SIMULATIONS}

For quantitative insights, we calibrate a numerical simulation model to replicate the broad characteristics of an economy with both regular and presumptive regimes. The production function is $f(L)=\beta L^{\alpha}$ and parameter values are selected such that: the average value added of a firm is about $\$ 120,000 ;{ }^{25}$ there is some bunching of firms just below the optimal threshold ${ }^{26}$ and the compliance cost is about $0.4 \%$ of the average turnover of firms in the regular regime. ${ }^{27}$ The formal sector output price is 1 USD and the informal sector good's price is normalized to 1 . The distribution of firms' unit costs is $H(c)=0.2 c^{2}+0.8 c^{3}$, with $c \in[0,1]$, capturing the preponderance of relatively high cost firms in most economies and generating a ratio of average value-added to sales equal to $26 \%$. The marginal value of public funds is set to 1.3. A summary of the baseline parameterizations is in lower-left cell of Table 2.

\footnotetext{
${ }^{25}$ The figure corresponds, e.g., to the value added per firm in Latvia, of 106,369 euro in 2017 (see European Commission, 2018).

${ }^{26}$ Bruhn and Loeprick (2016) provide evidence of bunching below the thresholds of the turnover tax regimes in Georgia.

${ }^{27}$ Corporate income tax compliance cost is between $0.05 \%$ and $15 \%$ of taxable turnover in developing and transition economies (Sapiei et al., 2014). Surveys of companies in Armenia and Ukraine suggest compliance costs comparable to our calibration for turnovers in the range of $\$ 150,000$ to $\$ 1$ million (Engelschalk and Loeprick, 2015). To fix $A$, we used the ratio of administrative cost to taxpayer compliance cost, based on estimates for VAT reported in Keen and Mintz (2004).
} 
Table 2 reports the optimal turnover tax rate and the optimal threshold at corporate tax rates ranging (exogenously) from $11 \%$ to $29 \%$. The row entitled "Placement of firms" shows the tax regimes firms choose (implicitly through their sales level) starting from the lowest cost segment of firms to the highest cost segment. ${ }^{28}$ When the corporate tax rate is low $\left(t^{c}=11 \%\right)$, the regular regime is not worth the compliance/administrative costs and the optimal threshold is very high, with all firms allocated to the presumptive regime. If $t^{c}$ is raised to $14 \%$, there is bunching at the threshold in the regular regime, whereas at higher corporate tax rates there is bunching just below the threshold. Increasing the corporate tax rate in steps from $17 \%$ to $26 \%$, the optimal threshold falls and the optimal turnover tax rate rises. ${ }^{29}$ Eventually, when $t^{c}$ is high enough $\left(t^{c}=29 \%\right)$, the distortion induced by the corporate income tax makes it optimal to again have all firms in the presumptive regime by setting an elevated threshold.

The last set of rows in Table 2 provide the global optimum at the baseline parameter values and the comparative statics analysis. The overall optimal policy occurs when the corporate income tax rate is $20.9 \%$ and the optimal turnover tax rate is $2.7 \%$, while the optimal threshold is $\$ 113,000$ and about $7 \%$ of firms bunch just below the threshold. ${ }^{30}$ A slight increase in the cost of compliance and administration (Case 1: $\Gamma=\$ 1300$ and $A=\$ 260$ ) leads to a decrease in the optimal threshold, as well as an increase in both the corporate tax rate and the presumptive tax rate. A slight increase in the marginal value of public funds (Case 2: $\delta=1.35$ ) leads to a decrease in the threshold, accompanied by an increase in both the corporate tax rate and the turnover tax rate. A slight increase in the productivity parameter $\beta$ (Case 3: $\beta=810$ ) leads to an increase in the threshold and in the tax rates.

Going beyond comparative statics, in Table 3 we fix the corporate income tax rate at $20 \%$ and consider how the optimal threshold and turnover tax rates vary at significantly different levels of economic development. However, such an exercise can only be taken as suggestive, rather than definitive, as we do not recalibrate the whole model for each country. Instead, we simply adjust the production function's shift parameter, $\beta$, to control the level of productivity in the economy. In reality, richer or poorer countries, relative to the baseline, likely have quite different distributions of firms in terms of marginal costs and their governments will have different marginal values of public funds. But there is insufficient data on most developing countries to calibrate individually and, moreover, attempting to do so could obscure the impacts of the different parameter configurations on the country-specific optimal tax policies. We take the following approach instead. The parameter $\beta$ is adjusted to achieve a target level of average value added per firm. As we do not have systematic data on the value added per firm for countries outside of the EU, we use data on GDP per person employed from the ILOSTAT database of the International Labour Organization to shift the value added per firm proportionately, relative to our benchmark simulation. We do this for three categories of coun-

\footnotetext{
${ }^{28}$ At the calibration used for Table 2 , there is no case of multiple equilibria at the optimal policy.

${ }^{29}$ Raising the corporate tax rate makes bunching more attractive, resulting in lost revenue. Lowering the threshold and increasing the turnover tax rate both serve to counter the incentive to bunch below the threshold.

${ }^{30}$ Though not shown in Table 2, the gross profit margins of firms bunching just below the threshold varies from $9 \%$ to $12 \%$ at the equilibrium. This shows the difficulty of applying the conventional wisdom, that the tax rates should be chosen to equalize the net returns of the marginal firm across tax regimes. When firms are heterogeneous, there is no unique profit margin on which to base the calculation of net returns.
} 
Table 3. Selected Regimes Comparison

\begin{tabular}{lllllll}
\hline \hline Selected Economy & $t^{*}$ & $\bar{Z}^{*}$ (\$ thousand) & Place of firms & Proportion of firms & $\begin{array}{l}\text { Average com- } \\
\text { pliance cost } / \\
\text { turnover }\end{array}$ & $\begin{array}{l}\text { Compliance } \\
\text { cost } / \text { turnover } \\
\text { at the threshold }\end{array}$ \\
Sub-Saharan Africa & $6.8 \%$ & 46 & R - B - P & $34 \%-14 \%-52 \%$ & $2.55 \%$ & $2.61 \%$ \\
Latin America & $3.6 \%$ & 92 & R - B - P & $57 \%-11 \%-32 \%$ & $0.72 \%$ & $1.30 \%$ \\
Euro Area & $2.0 \%$ & 150 & R - B - P & $76 \%-6 \%-18 \%$ & $0.25 \%$ & $0.80 \%$ \\
\hline \hline
\end{tabular}

tries, based on their group average, as reported in the ILOSTAT data: Sub-Saharan Africa, Latin America, and the Euro area, in ascending order of GDP per person employed. As Table 3 shows, the lower the average value added per firm, the lower is the optimal threshold and the higher is the turnover tax rate. The result for Sub-Saharan Africa stands out, as the optimal turnover tax rate is high, at $6.8 \%$, and a large proportion of firms are in the presumptive regime (including those bunching below the threshold), despite a relatively low threshold. These results are not unrealistic. For example, in Madagascar, firms with sales below \$56,000 face a turnover tax rate of $5 \%$, while the corporate income tax rate is $20 \%$.

\section{Conclusion}

Turnover-based presumptive business income tax systems are very common in developing and transition economies, where the compliance and administrative costs associated with corporate income taxation are highly regressive. In several OECD countries, including France, Italy, and Portugal, turnover taxes are applied to sole proprietorships meeting the sales threshold. This paper is the first to provide a theoretical analysis of the optimal turnover threshold and tax rate. The analysis provides insights on the key margins for setting the turnover threshold and tax rate, in relation to the corporate income rate, the importance of revenues for the government, and the size of compliance and administrative costs. A calibrated model suggests an optimal turnover tax rate of between 2 and 3 percent, with a threshold of around $\$ 115,000$, with some variation for countries at different levels of economic development. While the threshold value resembles the rule-of-thumb often used to recommend the VAT threshold, the margins of behavior between the VAT and a turnover tax are very different. A potentially important omission from our model is the economies of scope for taxpayer compliance and tax administration that may arise from using the same threshold for the presumptive tax on turnover as the VAT threshold. The joint determination of the thresholds for VAT and presumptive income taxation is an area for future research. ${ }^{31}$ The model assumes full compliance but allows for firms to restrict their output to remain below the threshold (bunching). Concerns frequently expressed, that presumptive tax regimes discourage small firms from growing, because they prefer not to be subjected to the regular corporate income tax, attest to the relevance of this form of adjustment of production. Future work can consider the additional

\footnotetext{
${ }^{31}$ Kanbur and Keen (2014) show some of the complexities arising from the interplay of the thresholds of different instruments.
} 
possibility that firms remain below the threshold by concealing their actual sales (Waseem, 2018). 


\section{REFERENCES}

Best, Michael Carlos, Brockmeyer, Anne, Kleven, Henrik Jacobsen, Spinnewijn, Waseem, Mazhar (2015) Production versus revenue efficiency with limited tax capacity : theory and evidence from Pakistan, Journal of Political Economy 123 (6): 1311-1355.

Blumenthal, Marsha, and Joel B. Slemrod (1996) The income tax compliance cost of big business, Public Finance Quarterly 24 (4) (October): 411-438.

Bruhn, Miriam, and Jan Loeprick (2016) Small business tax policy and informality: evidence from Georgia, International Tax and Public Finance 23 (5): 834-853.

Coolidge, Jaqueline, and Fatih Yilmaz (2016) Small business tax regimes, View point, note no. 349 (Washington DC: World Bank Group).

Coolidge, Jaqueline (2012) Findings of tax compliance cost surveys in developing countries, eJournal of Tax Research 10 (January): 250-287.

Dharmapala, Dhammika, Joel Slemrod, and John Douglas Wilson (2011) Tax policy and the missing middle: Optimal tax remittance with firm-level administrative costs, Journal of Public Economics 95 (9-10): 1036-1047.

Engelschalk, Michael, and Jan Loeprick (2015) MSME taxation in transition economies country experience on the costs and benefits of introducing special tax regimes, Policy Research Working Paper 7449, World Bank Group.

Gordon, Roger, and Wei Li (2009) Tax structures in developing countries: Many puzzles and a possible explanation, Journal of Public Economics 93 (7-8): 855-866.

International Monetary Fund (2007) Taxing small- and medium-sized enterprises, backgrounder paper for the International Tax Dialog conference, Buenos Aires, October 2007.

European Commission (2017) 2017 SBA fact sheet-Latvia.

Kanbur, Ravi, and Michael Keen (2014) Thresholds, informality, and partitions of compliance, International Tax and Public Finance 21 (4): 536-559.

Keen, Michael, and Jack Mintz (2004) The optimal threshold for a value-added tax, Journal of Public Economics 88 (3-4): 559-576.

Keen, Michael (2008) VAT, tariffs, and withholding: Border taxes and informality in developing countries, Journal of Public Economics 92 (10-11): 1892-1906. 
Kleven, Henrik J. and Mazhar Waseem (2013) Using notches to uncover optimizing frictions and structural elasticities: theory and evidence from Pakistan, Quarterly Journal of Economics 128 (2): 669-723.

Logue, Kyle D., and Gustavo G. Vettori (2011) Narrowing the Tax Gap Through Presumptive Taxation, Columbia Journal of Tax Law 2( 1): 100-149.

Medina, Leandro, and Friedrich Schneider (2018) Shadow economies around the world: what did we learn over the last 20 years?, IMF Working Paper No. 18/17, International Monetary Fund.

Sapiei, Noor Sharoja, Abdullah, Mazni, and Sulaiman, Noor Adwa (2014) Regressivity of the corporate taxpayersâÁŹ compliance costs, Procedia - Social and Behavioral Sciences 164: 26-31.

Waseem, Mazhar (2018) Taxes, informality and income shifting: evidence from a recent Pakistani tax reform, Journal of Public Economics 157 (January): 41-77. 


\section{APPENDIX: ProOfS}

\section{Proof of Proposition 2}

1. We have

$$
\begin{gathered}
D_{1}(c)=\pi^{R}-\pi^{B} \\
=\left[p^{R} f\left(L\left(p^{R}(c)\right)\right)+w\left(1-L\left(p^{R}(c)\right)\right)-\Gamma\right]-\left[p^{P}\left(\frac{\bar{Z}}{p}\right)+w(1-\mu(\bar{Z}))\right] \\
\frac{d\left(\pi^{R}-\pi^{B}\right)}{d c}=-\left(1-t^{c}\right) f\left(L\left(p^{R}\right)\right)+\frac{\bar{Z}}{p} \\
\frac{d^{2}\left(\pi^{R}-\pi^{B}\right)}{d c^{2}}=\left(1-t^{c}\right)^{2} f^{\prime} \frac{d L^{*}}{d p^{R}}>0
\end{gathered}
$$

where $\mu(\bar{Z})$ is the labor supply needed to generate the sales level $\bar{Z}$. Since $d^{2}\left(\pi^{R}-\right.$ $\left.\pi^{B}\right) / d c^{2}>0$, the function is strictly convex. It can therefore have at most two real roots.

2. We have

$$
\begin{aligned}
D_{2}(c)= & \pi^{A}-\pi^{B} \\
= & p^{R} \frac{\bar{Z}}{p}+w(1-\mu(\bar{Z}))-\Gamma-\left[p^{P} \frac{\bar{Z}}{p}+w(1-\mu(\bar{Z}))\right] \\
= & {\left[\left(t-t^{c}\right) p+t^{c} c\right] \frac{\bar{Z}}{p}-\Gamma } \\
& \frac{d\left(\pi^{A}-\pi^{B}\right)}{d c}=t^{c} \frac{\bar{Z}}{p}>0\left(\forall t^{c}>0\right)
\end{aligned}
$$

Hence, $D_{2}$ is linear and its unique real root is $c^{*}=\frac{(p \Gamma / \bar{Z})+\left(t^{c}-t\right) p}{t^{c}}$. Consequently, $\pi^{A}>$ $\pi^{B}$ for all $c \in\left[c^{*}, 1\right]$.

3. For strict quasi-concavity, we will establish that $D_{3}(c)$ is increasing over an interval $\left[0, c^{*}\right)$ and then decreasing over the remaining interval $\left[c^{*}, 1\right]$, or it is either decreasing or increasing throughout. Suppose, first, that $p^{P}(c) \geq 0$ for all firms. We have

$$
\begin{aligned}
& D_{3}(c)= \pi^{R}-\pi^{P} \\
&=\left[p^{R} f\left(L\left(p^{R}\right)\right)+w\left(1-L\left(p^{R}\right)\right)-\Gamma\right]-\left[p^{P} f\left(L\left(p^{P}\right)\right)+w\left(1-L\left(p^{P}\right)\right)\right] \\
& \frac{d\left(\pi^{R}-\pi^{P}\right)}{d c}=-\left(1-t^{c}\right) f\left(L\left(p^{R}\right)\right)+f\left(L\left(p^{P}\right)\right)
\end{aligned}
$$

using (9), (11) and (12). If $D_{3}$ attains an interior local maximum at some $c^{*}$, then it must be a solution to

$$
\left(1-t^{c}\right) f\left(L\left(p^{R}(c)\right)\right)=f\left(L\left(p^{P}(c)\right)\right)
$$


Now, ignore for the moment the term $\left(1-t^{c}\right)$ in (45) and consider graphing the curves $J \equiv f\left(L\left(p^{R}(c)\right)\right)$ and $K \equiv f\left(L\left(p^{P}(c)\right)\right) . J(c)$ and $K(c)$ are both continuously decreasing in $c$ :

$$
\begin{aligned}
\frac{d f(L(\rho(c)))}{d c} & =f^{\prime} \frac{d L}{d \rho} \frac{d \rho}{d c} \\
& =-\frac{\left(f^{\prime}\right)^{2}}{\rho f^{\prime \prime}}\left(\frac{d \rho}{d c}\right)<0
\end{aligned}
$$

using $d L / d \rho=-f^{\prime} /\left(\rho f^{\prime \prime}\right)$ from the differentiation of (3). We also know that $J(c)<$ $K(c)$ if and only if $p^{R}<p^{P}$; that is, $c<\frac{\left(t^{c}-t\right) p}{t^{c}}$, using the definitions of $p^{R}$ and $p^{P}$. Similarly, $J(c)>K(c)$ if and only if $p^{R}>p^{P}$. Thus, $J(c)$ intersects $K(c)$ from below at a unique value $\hat{c}^{*}$. (We do not require the curves to be concave or convex.)

Now, consider the effect of the term $\left(1-t^{c}\right)$ on the left-hand side of (45). Its effect is to rotate $J(c)$ downward from a fixed base at $c=p$; each point on the curve moves down by a fixed proportion $1-t^{c}$. Figure 7 illustrates the rotation in the curve. The curves $\left(1-t^{c}\right) J(c)$ and $K(c)$ intersect at $c^{*}$. The slope of $\left(1-t^{c}\right) J(c)$ is always greater than the slope of $J(c)$ (i.e., "less negative"). Furthermore, we will show that, at $c^{*}$, the slope of $J(c)$ is greater than the slope of $K(c)$ ("less negative"), which implies that the curve $\left(1-t^{c}\right) J(c)$ must always cut the curve $K(c)$ from below. We have $p^{R}>p^{P}$ at every point to the right of $\hat{c}^{*}$ and $c^{*}>\hat{c}^{*}$; it follows that the slope of $J(c)$ is greater ("less steep") than the slope of $K(c)$ at $c^{*}$, since

$$
\frac{d}{d \rho}\left(\frac{d f(L(\rho))}{\rho}\right)=\frac{-\left(f^{\prime}\right)^{2}}{\rho^{2}\left(f^{\prime \prime}\right)^{3}}\left(3\left(f^{\prime \prime}\right)^{2}-f^{\prime} f^{\prime \prime \prime}\right)>0
$$

using (46) and the assumption that $3\left(f^{\prime \prime}\right)^{2}-f^{\prime} f^{\prime \prime \prime}>0$.

Now suppose that the intersection between $\left(1-t^{c}\right) J(c)$ and $K(c)$ at $c^{*}$ is not unique. Then there is another point, to the right of $c^{*}$, where the curve $\left(1-t^{c}\right) J(c)$ intersects $K(c)$ from above. But we have just shown that this is impossible. Hence, there can only be one interior local maximum point of $D_{3}(c)$.

So far, we have ignored the possibility that there are values of $c \in[0,1]$ such that $p^{P} \leq$ 0 . At all $c$ such that $c \geq(1-t) p$, the firms in the presumptive regime would choose a corner solution with $L^{*}=0$ and $\pi^{P}=w$. Meanwhile, $d \pi^{R} / d c<0$ for all $c<1$. Hence, $D_{3}(c)$ is decreasing for all $c \geq(1-t) p$. Therefore, $D_{3}$ is decreasing over the whole interval $\left[c^{*}, 1\right]$ even when there exists a $\tilde{c}<1$ such that $p^{P}<0$ for all $c>\tilde{c}$. Finally, it is possible that $c^{*}$ (defined above) occurs outside of $c \in[0,1]$, in which case $D_{3}$ is decreasing throughout (when $c^{*} \leq 0$ ) or is increasing throughout (when $c^{*} \geq 1$ ). Both cases satisfy the definition of strict quasi-concavity.

4. For strict quasi-concavity, we will establish that $D_{4}(c)$ is increasing over an interval $\left[0, c^{* *}\right]$ and then decreasing over the remaining interval $\left[c^{* *}, 1\right]$, or it is decreasing through- 


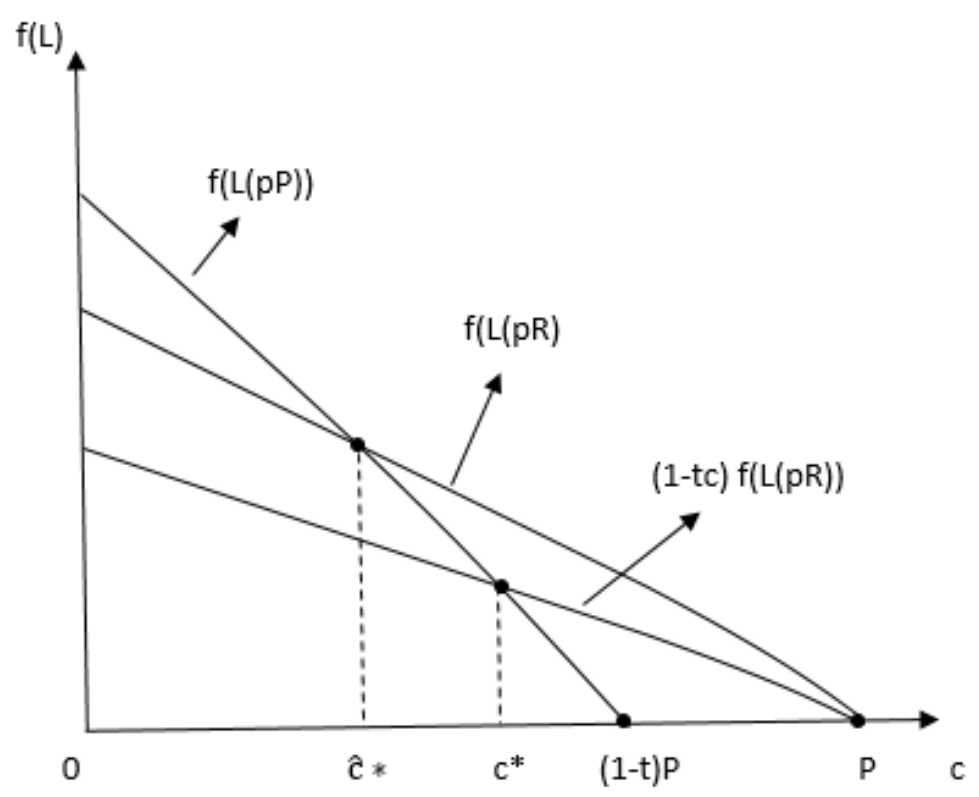

Figure 7. Unique maximum of $\pi^{R}(c)-\pi^{P}(c)$

out. Consider, first, firms with $p^{P}>0$ (i.e., $c<(1-t) p$ ). We have

$$
\begin{gathered}
D_{4}(c)=\pi^{A}-\pi^{P} \\
=\left[p^{R} \frac{\bar{Z}}{p}+w(1-\mu(\bar{Z}))-\Gamma\right]-\left[p^{P} f\left(L\left(p^{P}\right)\right)+w\left(1-L\left(p^{P}\right)\right)\right] \\
\frac{d\left(\pi^{A}-\pi^{P}\right)}{d c}=-\left(1-t^{c}\right) \frac{\bar{Z}}{p}+f\left(L\left(p^{P}\right)\right) \\
\frac{d^{2}\left(\pi^{A}-\pi^{P}\right)}{d c^{2}}=-f^{\prime} \frac{d L}{d p^{P}}<0
\end{gathered}
$$

Hence, for all $p^{P}>0, D_{4}(c)$ is strictly concave. So far, we have ignored the possibility that there are values of $c \in[0,1]$ such that $p^{P} \leq 0$. At all $c$ such that $c \geq(1-t) p$, the firms in the presumptive regime would choose a corner solution with $L^{*}=0$ and $\pi^{P}=$ $w$. Meanwhile $d \pi^{A} / d c<0$ for all $c<1$. Hence, $D_{4}(c)$ is decreasing for all $c \geq(1-$ $t) p$. Thus, $D_{4}$ is either a decreasing function throughout $c \in[0,1]$ or it is increasing over some range $\left[0, c^{* *}\right)$ and then decreasing over the range $\left[c^{* *}, 1\right]$. In either case, $D_{4}$ is strictly quasi-concave. 


\section{Proof of Proposition 4}

$$
\begin{aligned}
\frac{d S W}{d \bar{Z}} & =\left[p^{R}\left(c_{1}\right) f\left(L\left(p^{R}\left(c_{1}\right)\right)\right)+w\left(1-L\left(p^{R}\left(c_{1}\right)\right)\right)-\Gamma\right] h\left(c_{1}\right) \frac{d c_{1}}{d \bar{Z}} \\
& +\left[p^{P}\left(c^{\prime}\right) \frac{\bar{Z}}{p}+w(1-\mu(\bar{Z}))\right] h\left(c^{\prime}\right) \frac{d c^{\prime}}{d \bar{Z}}-\left[p^{P}\left(c_{1}\right) \frac{\bar{Z}}{p}+w(1-\mu(\bar{Z}))\right] h\left(c_{1}\right) \frac{d c_{1}}{d \bar{Z}} \\
& +\int_{c_{1}}^{c^{\prime}}\left[p^{P} \frac{1}{p}-w \mu_{\bar{Z}}\right] h(c) d c-\left[p^{P}\left(c^{\prime}\right) f\left(L\left(p^{P}\left(c^{\prime}\right)\right)\right)+w\left(1-L\left(p^{P}\left(c^{\prime}\right)\right)\right)\right] h\left(c^{\prime}\right) \frac{d c^{\prime}}{d \bar{Z}} \\
& +\delta\left\{\left[t^{c}\left(p-c_{1}\right) f\left(L\left(p^{R}\left(c_{1}\right)\right)\right)-A\right] h\left(c_{1}\right) \frac{d c_{1}}{d \bar{Z}}+\int_{c_{1}}^{c^{\prime}} t p \frac{1}{p} h(c) d c\right. \\
& \left.+t p \frac{\bar{Z}}{p}\left[h\left(c^{\prime}\right) \frac{d c^{\prime}}{d \bar{Z}}-h\left(c_{1}\right) \frac{d c_{1}}{d \bar{Z}}\right]-t p f\left(L\left(p^{P}\left(c^{\prime}\right)\right)\right) h\left(c^{\prime}\right) \frac{d c^{\prime}}{d \bar{Z}}\right\} \\
& =0
\end{aligned}
$$

Using the definitions of $c_{1}$ and $c^{\prime}$ to cancel terms, the expression simplifies to

$$
\begin{aligned}
\frac{d S W}{d \bar{Z}} & =\int_{c_{1}}^{c^{\prime}}\left[p^{P} \frac{1}{p}-w \mu_{\bar{Z}}\right] h(c) d c+\delta \int_{c_{1}}^{c^{\prime}} t p \frac{1}{p} h(c) d c \\
& +\delta\left[t^{c}\left(p-c_{1}\right) f\left(L\left(p^{R}\left(c_{1}\right)\right)\right)-A-t p \frac{\bar{Z}}{p}\right] h\left(c_{1}\right) \frac{d c_{1}}{d \bar{Z}} \\
& =0
\end{aligned}
$$

Rearranging the equation generates the proposition.

\section{Proof of Proposition 5}

$$
\begin{aligned}
\frac{d S W}{d t} & =\left[p^{R}\left(c_{1}\right) f\left(L\left(p^{R}\left(c_{1}\right)\right)\right)+w\left(1-L\left(p^{R}\left(c_{1}\right)\right)\right)-\Gamma\right] h\left(c_{1}\right) \frac{d c_{1}}{d t} \\
& +\left[p^{P}\left(c^{\prime}\right) \frac{\bar{Z}}{p}+w(1-\mu(\bar{Z}))\right] h\left(c^{\prime}\right) \frac{d c^{\prime}}{d t}-\left[p^{P}\left(c_{1}\right) \frac{\bar{Z}}{p}+w(1-\mu(\bar{Z}))\right] h\left(c_{1}\right) \frac{d c_{1}}{d t} \\
& +\int_{c_{1}}^{c^{\prime}}\left(-p \frac{\bar{Z}}{p}\right) h(c) d c-\left[p^{P}\left(c^{\prime}\right) f\left(L\left(p^{P}\left(c^{\prime}\right)\right)\right)+w\left(1-L\left(p^{P}\left(c^{\prime}\right)\right)\right)\right] h\left(c^{\prime}\right) \frac{d c^{\prime}}{d t} \\
& +\int_{c^{\prime}}^{1}\left[-p f\left(L\left(p^{P}\right)\right)\right] h(c) d c \\
& +\delta\left\{\left[t^{c}\left(p-c_{1}\right) f\left(L\left(p^{R}\left(c_{1}\right)\right)\right)-A\right] h\left(c_{1}\right) \frac{d c_{1}}{d t}+\int_{c_{1}}^{c^{\prime}}\left(p \frac{\bar{Z}}{p}\right) h(c) d c\right. \\
& +t p \frac{Z}{p}\left[h\left(c^{\prime}\right) \frac{d c^{\prime}}{d t}-h\left(c_{1}\right) \frac{d c_{1}}{d t}\right]+\int_{c^{\prime}}^{1}\left[p f\left(L\left(p^{P}\right)\right)\right] h(c) d c \\
& \left.-t p f\left(L\left(p^{P}\left(c^{\prime}\right)\right)\right) h\left(c^{\prime}\right) \frac{d c^{\prime}}{d t}+\int_{c^{\prime}}^{1}\left[-t p^{2} f^{\prime} \frac{d L}{d p^{P}}\right] h(c) d c\right\}
\end{aligned}
$$


Using the definitions of $c_{1}$ and $c^{\prime}$ to cancel terms, the expression simplifies to

$$
\begin{aligned}
\frac{d S W}{d t} & =-\int_{c_{1}}^{c^{\prime}} p \frac{\bar{Z}}{p} h(c) d c-\int_{c^{\prime}}^{1} p f\left(L\left(p^{P}\right)\right) h(c) d c \\
& +\delta \int_{c_{1}}^{c^{\prime}} p \frac{\bar{Z}}{p} h(c) d c+\delta \int_{c^{\prime}}^{1} p f\left(L\left(p^{P}\right)\right) h(c) d c-\delta \int_{c^{\prime}}^{1} t p^{2} f^{\prime} \frac{d L}{d p^{P}} h(c) d c \\
& +\delta\left[t^{c}\left(p-c_{1}\right) f\left(L\left(P^{R}\left(c_{1}\right)\right)\right)-A-t p \frac{\bar{Z}}{p}\right] h\left(c_{1}\right) \frac{d c_{1}}{d t} \\
& =0
\end{aligned}
$$

Rearranging the equation generates the proposition.

\section{First-order condition of welfare for $t^{c}$}

$$
\begin{aligned}
\frac{d S W}{d t^{c}} & =\int_{0}^{c_{1}}\left[-(p-c) f\left(L\left(p^{R}\right)\right)\right] h(c) d c \\
& +\left[p^{R}\left(c_{1}\right) f\left(L\left(p^{R}\left(c_{1}\right)\right)\right)+w\left(1-L\left(p^{R}\left(c_{1}\right)\right)\right)-\Gamma\right] h\left(c_{1}\right) \frac{d c_{1}}{d t^{c}} \\
& +\left[p^{P}\left(c^{\prime}\right) \frac{\bar{Z}}{p}+w(1-\mu(\bar{Z}))\right] h\left(c^{\prime}\right) \frac{d c^{\prime}}{d t^{c}}-\left[p^{P}\left(c_{1}\right) \frac{\bar{Z}}{p}+w(1-\mu(\bar{Z}))\right] h\left(c_{1}\right) \frac{d c_{1}}{d t^{c}} \\
& -\left[p^{P}\left(c^{\prime}\right) f\left(L\left(p^{P}\left(c^{\prime}\right)\right)\right)+w\left(1-L\left(p^{P}\left(c^{\prime}\right)\right)\right)\right] h\left(c^{\prime}\right) \frac{d c^{\prime}}{d t^{c}} \\
& +\delta\left\{\int_{0}^{c_{1}}(p-c) f\left(L\left(p^{R}\right)\right) h(c) d c+\int_{0}^{c_{1}}\left[-t^{c}(p-c)^{2} f^{\prime} \frac{d L}{d p^{R}}\right] h(c) d c\right. \\
& \left.-t p \frac{\bar{Z}}{p} h\left(c_{1}\right) \frac{d c_{1}}{d t^{c}}\right\} \\
& =0
\end{aligned}
$$

Using the definitions of $c_{1}$ and $c^{\prime}$ to cancel terms, the expression simplifies to

$$
\begin{aligned}
\frac{d S W}{d t^{c}} & =(\delta-1) \int_{0}^{c_{1}}(p-c) f\left(L\left(p^{R}\right)\right) h(c) d c \\
& -\delta \int_{0}^{c_{1}}\left[t^{c}(p-c) f^{\prime} \frac{d L}{d p^{R}}(p-c)\right] h(c) d c \\
& +\left[t^{c}\left(p-c_{1}\right) f\left(L\left(p^{R}\left(c_{1}\right)\right)\right)-A-t p \frac{\bar{Z}}{p}\right] h\left(c_{1}\right) \frac{d c_{1}}{d t^{c}} \\
& =0
\end{aligned}
$$

